\title{
Self-Aggregation in Pyrrole: Matrix Isolation, Solid State Infrared Spectroscopy, and DFT Study
}

\author{
Andrea Gómez-Zavagliaa ${ }^{\dagger, *}$ and Rui Fausto ${ }^{*, \dagger}$ \\ Department of Chemistry, University of Coimbra, P-3004-535, Portugal, and \\ Facultad de Farmacia y Bioquímica, Universidad de Buenos Aires, RA-1113, Argentina
}

Received: April 30, 2004; In Final Form: June 15, 2004

\begin{abstract}
Pyrrole $\left(\mathrm{C}_{4} \mathrm{H}_{5} \mathrm{~N}\right)$ was embedded in low-temperature solid inert matrixes (argon, xenon; $T=9 \mathrm{~K}$ ) and both the monomer and low-order aggregates characterized by FTIR spectroscopy. The spectroscopic studies were complemented by extensive theoretical [DFT(B3LYP)/6-311++G(d,p)] structural and vibrational studies carried out for the monomer and their self-aggregates (up to four units). The calculated spectrum for monomeric pyrrole fits well those obtained immediately after deposition (at $9 \mathrm{~K}$ ) of diluted matrixes, which can be prepared keeping the compound at low temperature before deposition and using low fluxes of the sublimate. Annealing of the matrixes to higher temperatures or increasing of the gaseous flux during deposition leads to aggregation, which can be easily recognized spectroscopically. On the basis of the theoretically predicted spectra for the monomer, dimer, trimers, and tetramers of pyrrole, assignments were proposed for the experimentally observed bands. It was also found that the formation of the hydrogen-bonded clusters shows a significant cooperativity effect, which was studied in detail and could be related with several structural and spectroscopic parameters. Infrared spectra of the pure solid compound at low temperatures in both amorphous and crystalline states were also studied and interpreted.
\end{abstract}

\section{Introduction}

Pyrrole $\left(\mathrm{C}_{4} \mathrm{H}_{5} \mathrm{~N}\right)$ is a five-membered aromatic ring system containing one nitrogen atom. The pyrrole moiety is one of the ubiquitous heterocyclic structures throughout both the plant and animal kingdoms, because it is a subunit of both the hemes and the chlorophylls. The biosynthetically related vitamin $\mathrm{B}_{12}$ is also a tetrapyrrole, as are the animal and plant bile pigments. Monopyrrolic natural products include porphobilinogen, the precursor of all natural pyrrole pigments based on the porphyrin or corrin nuclei, and a number of antibiotics, including the tripyrrolic prodigiosins, which have an entirely different biosynthetic origin. ${ }^{1}$ This widespread appearance of the pyrrole moiety among biological molecules is mainly due to both its facility to polymerize and capacity to form $\mathrm{N}-\mathrm{H} \cdots \pi$ hydrogen bonds with neighboring molecules. ${ }^{2-7}$

The gaseous phase of pyrrole has been studied long time ago by means of microwave spectroscopy ${ }^{8,9}$ and electron diffraction. ${ }^{10}$ Very interestingly, Wilcox and Goldstein, the authors of the first microwave study on pyrrole (published in 1952), mainly addressed the question of whether the pyrrole molecule is completely coplanar or not (doubts existed at that time regarding the precise position of the hydrogen atom bonded to the nitrogen ${ }^{11}$ ). Subsequent microwave studies of pyrrole and some of its isotopologues ${ }^{9,12}$ enabled researchers to answer affirmatively to this question and obtain the complete set of geometrical parameters for the molecule. Rotational transitions of the dimer were also identified in the microwave spectrum of pyrrole, and a partial structure for that species was determined. ${ }^{13}$ The dimer was found to have an approximate $\mathrm{T}$-shaped structure, the planes of the two pyrrole units forming an angle of $55.4^{\circ}$,

* Corresponding author. E-mail: rfausto@ci.uc.pt.

$\dagger$ University of Coimbra.

$\doteqdot$ Universidad de Buenos Aires. with the nitrogen side of one ring directed to the $\pi$ electron system of the other ring, forming a $\mathrm{N}-\mathrm{H} \cdots \pi$ hydrogen bond.

High-quality structural calculations on pyrrole have been centered essentially on the study of the monomer. ${ }^{14-23}$ Lower level calculations on the pyrrole dimer have also been reported..$^{24-29}$ In agreement with the microwave data, ${ }^{13}$ and contrarily to the benzene molecule whose potential energy surface (PES) exhibits three different minima, ${ }^{30-33}$ the theoretical studies lead to the conclusion that the pyrrole dimer has a single T-shaped minimum on its PES. ${ }^{24}$ At the DFT(B3LYP)/ $6-31++\mathrm{G}(\mathrm{d}, \mathrm{p})$ level of theory, ${ }^{24}$ the interplanar angle between the two monomeric units was predicted to be ca. $73^{\circ}$. To our knowledge, no calculations regarding pyrrole self-aggregates of more than two units were performed.

The crystal structure of solid pyrrole was determined in 1997 by X-ray diffraction. ${ }^{34}$ The crystal is orthorhombic, with four molecules per unit cell and characterized by an $\mathrm{N}-\mathrm{H} \cdots \pi$ interaction between neighboring molecules. The strongest intermolecular interaction found in the crystal closely resembles that found for the gaseous phase dimer, with the $\mathrm{N}-\mathrm{H}$ bond pointing almost directly at the midpoint of the $\mathrm{C}-\mathrm{C}$ bond and intersecting the plane of the pyrrole ring at an angle of $70^{\circ}$ at this point. The bond distances in the crystal were also found to be comparable to those obtained by microwave spectroscopy and predicted theoretically for the pyrrole monomer and dimer. $9,12,15,24$

Experimental vibrational spectra of pyrrole have been reported a long time ago. ${ }^{35-37}$ Although the first infrared spectrum was published during the first decade of the 20th century, ${ }^{38}$ the first comprehensive work on the vibrational spectroscopy of pyrrole was carried out in 1942 by Lord and Miller. ${ }^{39}$ They published infrared and Raman data and presented band assignments for the compound and several deuterated isotopologues $(\mathrm{N}-\mathrm{D}$; $\mathrm{C}-\mathrm{D}_{4}$ and $\left.-\mathrm{D}_{5}\right)$ in the liquid state. Within the next two decades, 
the vapor phase, liquid, and solution (in $\mathrm{CCl}_{4}$ ) IR spectra of pyrrole and isotopically substituted derivatives were studied by Mirone and by Morcillo and Orza. ${ }^{40,41}$ The vibrational signature of the compound was found to obey to the predictions made based on a $C_{2 v}$ symmetry geometry for the monomer. ${ }^{40-43}$ Several empirical force fields were derived from these older spectroscopic results. ${ }^{42-45}$ More recently, the vibrational spectra of pyrrole were investigated under different experimental conditions: gas phase, ${ }^{36,46-51}$ pure liquid, ${ }^{24,36,48,52-56}$ crystalline state, ${ }^{57}$ jet cooled, ${ }^{46,50,58}$ solution, ${ }^{36,56}$ and adsorbed on metal surfaces and zeolites. ${ }^{59,60}$ In some of these spectroscopic studies, the interpretation of the experimental data was supported by theoretical calculations undertaken at different levels of theory. ${ }^{23,24,49,50,52,58}$ In the recent years, the emphasis was put on the study of anharmonicity and assignment of overtones and combination tones. ${ }^{16,17,20,47,51}$

Very interestingly, despite the previous extensive investigation of the vibrational spectra of pyrrole, this molecule has not been studied by matrix isolation spectroscopy yet. The high tendency of pyrrole to aggregate is, without any doubt, the main factor responsible for the difficulty in isolating the molecule in matrixes. Not surprisingly, among the simplest five-membered aromatic heterocycles (pyrrole, furane, and thiophene) only thiophene (the member that has the lowest tendency to aggregate) has already been isolated in matrixes. ${ }^{61}$ In the matrix spectra, the effect of heterogeneous band broadening nearly vanishes in comparison with the condensed phase, and unlike the gaseous state, the fine rotational structure is completely absent. Furthermore, unlike the solutions, it is in principle possible to neglect the effect of an inert matrix environment on the structure of molecules. These factors result in a unique narrowing of bands in vibrational spectra (usually down to a few tenths of a wavenumber), which makes it possible to detect the band shifts of a few wavenumbers that are characteristic for the finest changes of a sample's structure. Moreover, because the inert matrix only slightly affects the structure of isolated molecules it is possible to compare directly matrix experimental results and theoretically calculated spectra. In addition, by controlling the deposition conditions and concentration of the matrixes and by annealing of the matrixes at proper temperatures it is possible to control the amount of aggregates present in the matrixes. All these characteristics of matrix isolation spectroscopy make it a very convenient method for investigating the vibrational signature and aggregation processes of pyrrole.

We have been developing a very efficient experimental procedure for isolation in low-temperature matrixes of volatile compounds exhibiting great tendency to aggregate, which takes advantage of the doubly thermostatable cell developed in our laboratory. ${ }^{62}$ This fact encouraged us to apply our approach to the study of monomeric pyrrole and its self-aggregates isolated in low-temperature inert matrixes (Ar, Xe). The spectroscopic studies were supported by extensive theoretical [DFT(B3LYP)/ 6-311++G(d,p)] structural and vibrational studies of pyrrole and their small aggregates (up to four units). This strategy allowed us for the first time, not only to isolate pyrrole in matrixes and assign the bands corresponding to the monomer, but also to get a deeper insight into the vibrational spectroscopic manifestations of the self-aggregates of pyrrole and the $\mathrm{H}$ bonding in this molecular system. Since hydrogen bonds can be expected to be the main intermolecular forces involved in pyrrole aggregates, the importance of hydrogen bond cooperativity on the stability of these species was here investigated in detail.

\section{Experimental and Computational Methods}

Infrared Spectroscopy. Pyrrole was obtained in spectroscopic grade from Argos Organics (99\% purity). The IR spectra were collected on a Mattson (Infinity 60AR Series) Fourier transform infrared spectrometer equipped with a deuterated triglycine sulfate (DTGS) detector and a $\mathrm{Ge} / \mathrm{KBr}$ beam splitter, with $0.5 \mathrm{~cm}^{-1}$ spectral resolution. Necessary modifications of the sample compartment of the spectrometer were made in order to accommodate the cryostat head and allow efficient removal of water and $\mathrm{CO}_{2}$ vapors from the instrument by a stream of pretreated air.

In the matrix isolation experiments, a glass vacuum system and standard manometric procedures were used to deposit the matrix gas (argon, N60; xenon, N45; both obtained from Air Liquid). Matrixes were prepared by codeposition, onto the cooled CsI substrate of the cryostat, of the matrix gas and pyrrole placed in a specially designed doubly thermostatable Knudsen cell ${ }^{62}$ with shut-off possibility whose main component is a NUPRO SS-4BMRG needle valve. The temperature of the cell can be controlled separately in the valve nozzle and the sample compartment, enabling a more precise control of the saturated gas pressure over the liquid pyrrole and a better metering function of the valve. Further details of the experimental setup can be found in ref 62. All experiments were done based on an APD Cryogenics close-cycle helium refrigeration system with a DE-202A expander. The deposition temperature used was 9 $\mathrm{K}$ for both argon and xenon matrixes. After depositing the compound, annealing experiments were performed $\left(T_{\max }=30\right.$ or $60 \mathrm{~K}$ for $\mathrm{Ar}$ and $\mathrm{Xe}$, respectively).

The low-temperature solid amorphous layer was prepared in the same way as the matrixes, but with the flux of matrix gas cut off. The layer was then allowed to anneal at slowly increasing temperature up to $180 \mathrm{~K}$. IR spectra were collected during this process every $10-20 \mathrm{~K}$ of temperature change.

Computational Methodology. All calculations were carried out with Gaussian 98 (revision A 3.0). ${ }^{63}$ The DFT calculations were performed using the three-parameter density functional abbreviated as B3LYP, which includes Becke's gradient exchange correction ${ }^{64}$ and the Lee, Yang, Parr correlation functional, ${ }^{65}$ with the $6-311++\mathrm{G}(\mathrm{d}, \mathrm{p})$ basis set. ${ }^{66}$ The level of theory was selected taking into consideration the available information on the good general quality of the B3LYP functional to deal with intermolecular forces, in particular, hydrogen bonding. ${ }^{67-70}$ All structures were optimized using the geometry direct inversion of the invariant subspace (GDIIS) method, ${ }^{71}$ with the TIGHT convergence criteria defined in Gaussian. Calculations were undertaken with and without symmetry constrains, all calculations converging to the symmetrical structures discussed in detail in the next sections. For all calculated structures, vibrational frequencies were calculated at the same level of theory and scaled down by a single factor (0.978) to correct them for the effects of basis set limitations, neglected part of electron correlation, and anharmonicity effects. The value of the scaling factor has been chosen in consonance with previously reported calculations, performed at the same level of theory on other molecules containing first row elements and where H-bonding was found to play an important role. ${ }^{69,70,72}$

Corrections to calculated energies due to basis set superposition error (BSSE) were obtained by the full counterpoise procedure. ${ }^{73}$ For a complex between $N$ molecules $(N \geq 2)$, the BSSE correction is described by the following equation

$$
\operatorname{BSSE}(N)=\sum_{i=1, N}\left[E\left(X_{i}\right)_{X i}-E\left(X_{i}\right)_{N}\right]
$$




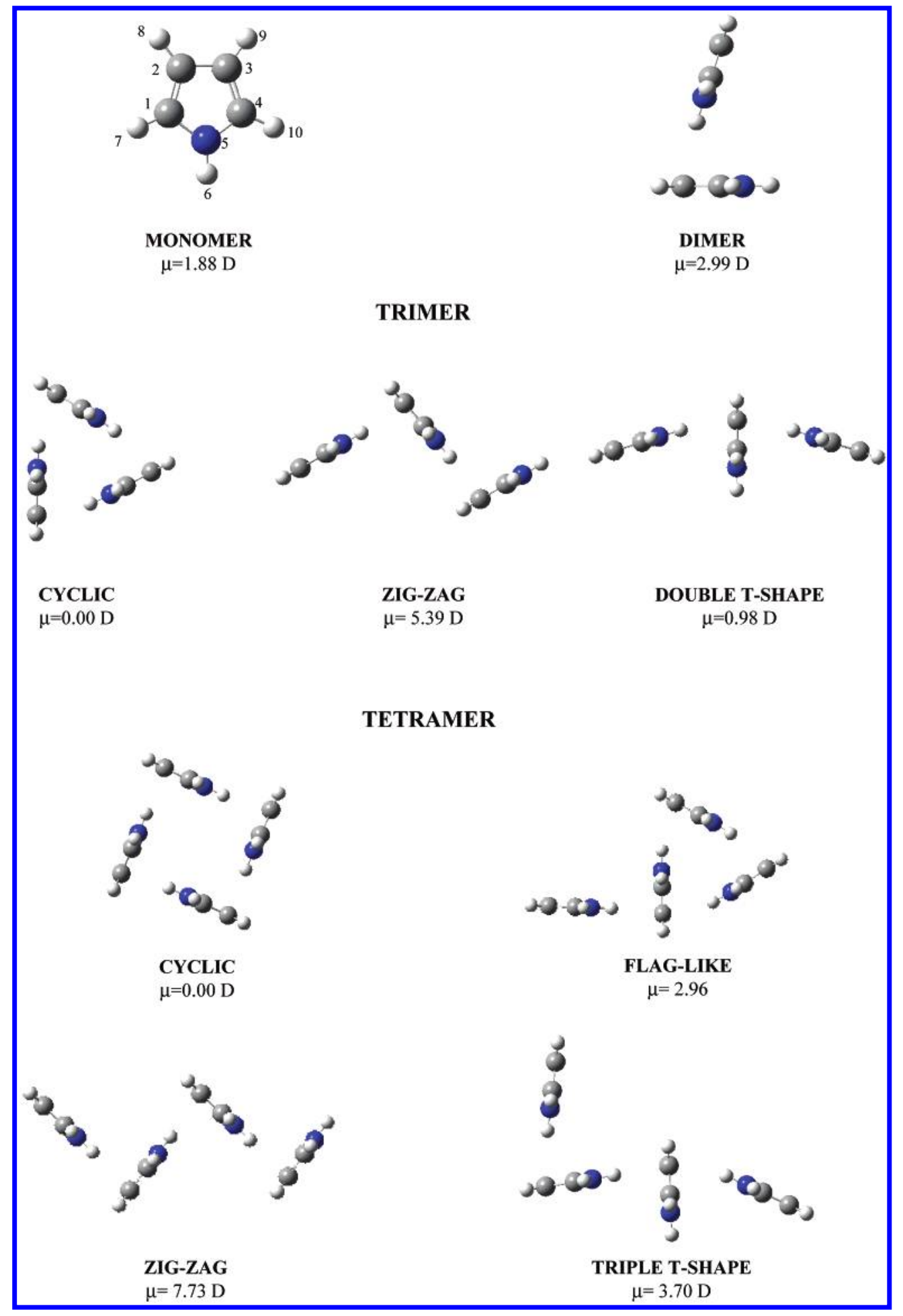

Figure 1. DFT(B3LYP)/6-31++G(d,p)-calculated structures and dipole moments of pyrrole and its self-aggregates up to four pyrrole units.

where $E\left(X_{i}\right)_{X i}$ represents the energy of molecule $X_{i}$ using its own basis functions and $E\left(X_{i}\right)_{N}$ represents the energy of molecule $X_{i}$ using the complete set of basis functions of the complex of $N$ molecules. In both cases, the geometries used were those calculated for a given molecule in the complex.

Intermolecular stabilization energies at $0 \mathrm{~K}\left(\Delta E_{\text {int }}\right)$ were calculated using the supramolecular approach, which is described as the difference between the energy of the supramolecular aggregate and that of the isolated monomers, corrected for BSSE.

\section{Results and Discussion}

Geometries and Energies. Figure 1 depicts the geometries and dipole moments of monomeric pyrrole and small selfaggregates up to four units. Calculated energies and geometries are given in Tables 1 and 2 .

The monomer shows $C_{2 v}$ symmetry, whereas the dimer has $C_{s}$ symmetry, with the interplanar angle between the two monomeric units equal to $71.6^{\circ}$. In the case of the trimer, three different structures were obtained: the lowest energy trimer has $C_{3 h}$ symmetry, being a cyclic structure where the angles between 
TABLE 1: DFT(B3LYP)/6-311++G(d,p) Energetic Data for the Monomer of Pyrrole and Small Self-Aggregates ${ }^{a}$

\begin{tabular}{|c|c|c|c|c|c|c|c|c|c|c|c|c|}
\hline & $\begin{array}{l}\text { number of } \\
\text { monomers } \\
(N)\end{array}$ & $E(N)$ & BSSE & $\begin{array}{c}\mathrm{ZPV} \\
E \times 0.978\end{array}$ & $\begin{array}{c}\Delta(E(N)+ \\
\mathrm{BSSE})^{b}\end{array}$ & $\begin{array}{c}{[\Delta E(N)+} \\
\mathrm{BSSE}+ \\
\mathrm{ZPV} \\
E \times 0.978]\end{array}$ & $\Delta E(\mathrm{HB})^{c}$ & $\begin{array}{l}\Delta E(\mathrm{HB}) \\
\text { corrected } \\
\text { by BSSE }\end{array}$ & $\Delta H_{0}(\mathrm{HB})$ & $\begin{array}{c}\% C \\
{[\Delta E(\mathrm{HB})]}\end{array}$ & $\begin{array}{c}\% C \\
{[\Delta E(\mathrm{HB})]} \\
\text { corrected } \\
\text { by BSSE }\end{array}$ & $\begin{array}{c}\% C \\
{\left[\Delta H_{0}(\mathrm{HB})\right]}\end{array}$ \\
\hline 1 & & -551960.41 & & 211.04 & & & & & & & & \\
\hline 2 & & -1103934.90 & 1.63 & 424.66 & & & -4.10 & -12.47 & -9.88 & & & \\
\hline 3 & cyclic & -1655928.38 & 4.89 & 640.34 & & & -15.73 & -14.10 & -11.69 & 11.6 & 13.1 & 18.3 \\
\hline 3 & zigzag & -1655911.26 & 3.41 & 637.98 & 15.63 & 13.26 & -15.05 & -13.34 & -10.90 & 6.7 & 7.0 & 10.4 \\
\hline 3 & $\begin{array}{l}\text { double } \\
\text { T-shaped }\end{array}$ & -1655905.89 & 3.12 & 637.54 & 20.73 & 17.93 & -12.35 & -10.79 & -8.57 & -12.4 & -13.5 & -13.3 \\
\hline 4 & cyclic & -2207911.45 & 7.00 & 852.86 & & & -17.48 & -15.72 & -13.54 & 23.9 & 26.0 & 37.0 \\
\hline 4 & zigzag & -2207888.54 & 5.21 & & 21.20 & & -15.63 & -13.90 & & 10.9 & 11.4 & \\
\hline 4 & flaglike & -2207900.33 & 6.48 & & 10.65 & & -14.68 & -13.06 & & 4.1 & 4.7 & \\
\hline 4 & triple & -2207881.60 & 4.92 & & 27.81 & & -13.33 & -11.69 & & -5.4 & -6.3 & \\
\hline
\end{tabular}

${ }^{a}$ Energies in $\mathrm{kJ} \mathrm{mol}^{-1}$; structures are depicted in Figure 1. ${ }^{b}$ Relative values to the most stable structure of the same $N .{ }^{c} \Delta E(\mathrm{HB})$ is the average energy of H-bonding and corresponds to the binding energy $[E(N)-N \times E(1)] / n(\mathrm{HB})$, where $E(N)$ is the energy of the cluster, $E(1)$ is the energy of the monomer, and $n(\mathrm{HB})$ is the number of $\mathrm{H}$-bonds in a given cluster.

TABLE 2: Experimental and Calculated [DFT(B3LYP)/6-311++G(d,p)] Geometries for Pyrrole and Their Most Stable Small Aggregates $^{a}$

\begin{tabular}{|c|c|c|c|c|c|c|c|}
\hline \multirow[b]{2}{*}{ parameter } & \multicolumn{2}{|c|}{ monomer } & \multicolumn{3}{|c|}{$\begin{array}{c}\text { dimer } \\
\text { (T-shaped) }\end{array}$} & \multirow{2}{*}{$\begin{array}{c}\text { trimer } \\
(\text { cyclic })\end{array}$} & \multirow{2}{*}{$\begin{array}{c}\begin{array}{c}\text { tetramer } \\
\text { (cyclic) }\end{array} \\
\text { calcd }\end{array}$} \\
\hline & exptl $^{12}$ & calcd & $\operatorname{exptl}^{13}$ & & & & \\
\hline \multicolumn{8}{|c|}{ Bond Lengths / pm } \\
\hline $\mathrm{C}_{1}=\mathrm{C}_{2} ; \mathrm{C}_{4}=\mathrm{C}_{3}$ & 138.2 & 137.7 & & $137.8^{b}$ & $137.8^{c}$ & 138.1 & 138.1 \\
\hline $\mathrm{C}_{1}-\mathrm{N}_{5} ; \mathrm{C}_{4}-\mathrm{N}_{5}$ & 137.0 & 137.5 & & $137.3^{b}$ & $137.4^{c}$ & 137.0 & 137.0 \\
\hline $\mathrm{C}_{1}-\mathrm{H}_{7} ; \mathrm{C}_{4}-\mathrm{H}_{10}$ & 107.6 & 107.8 & & $107.8^{b}$ & $107.8^{c}$ & 107.8 & 107.8 \\
\hline $\mathrm{C}_{2}-\mathrm{C}_{3}$ & 141.7 & 142.5 & & $142.4^{b}$ & $142.7^{c}$ & 142.0 & 142.7 \\
\hline $\mathrm{C}_{2}-\mathrm{H}_{8} ; \mathrm{C}_{3}-\mathrm{H}_{9}$ & 107.7 & 107.8 & & $107.9^{b}$ & $107.9^{c}$ & 107.9 & 107.9 \\
\hline $\mathrm{N}_{5}-\mathrm{H}_{6}$ & 99.6 & 100.6 & & $101.1^{b}$ & $100.7^{c}$ & 101.3 & 101.4 \\
\hline$R_{\text {centers of mass }}$ & & 23.7 & 411.6 & \multirow{2}{*}{\multicolumn{2}{|c|}{452.9}} & 435.3 & $457.6^{d} / 647.1^{e}$ \\
\hline$R(\mathrm{NH} \cdots \pi)$ & & & & \multirow{2}{*}{\multicolumn{2}{|c|}{$\begin{array}{l}252.0 \\
370.9\end{array}$}} & 248.7 & 237.0 \\
\hline$R_{\mathrm{NN}}$ & & & & & & 351.8 & $387.0^{d} / 547.3^{e}$ \\
\hline \multicolumn{8}{|c|}{ Bond Angles/ deg } \\
\hline $\mathrm{C}_{2}-\mathrm{C}_{1}-\mathrm{N}_{5} ; \mathrm{C}_{3}-\mathrm{C}_{4}-\mathrm{N}_{5}$ & 107.7 & 107.7 & & $107.9^{b}$ & $107.7^{c}$ & 107.9 & 107.9 \\
\hline $\mathrm{C}_{2}-\mathrm{C}_{1}-\mathrm{H}_{7} ; \mathrm{C}_{3}-\mathrm{C}_{4}-\mathrm{H}_{10}$ & 130.8 & 131.1 & & $131.0^{b}$ & $131.1^{c}$ & 131.0 & 131.0 \\
\hline $\mathrm{N}_{5}-\mathrm{C}_{1}-\mathrm{H}_{7} ; \mathrm{N}_{5}-\mathrm{C}_{4}-\mathrm{H}_{10}$ & 121.5 & 121.3 & & $121.1^{b}$ & $121.3^{c}$ & 121.1 & 121.1 \\
\hline $\mathrm{C}_{1}-\mathrm{C}_{2}-\mathrm{C}_{3} ; \mathrm{C}_{2}-\mathrm{C}_{3}-\mathrm{C}_{4}$ & 107.4 & 107.4 & & $107.3^{b}$ & $107.4^{c}$ & 107.3 & 107.2 \\
\hline $\mathrm{C}_{1}-\mathrm{C}_{2}-\mathrm{H}_{8} ; \mathrm{C}_{4}-\mathrm{C}_{3}-\mathrm{H}_{9}$ & 125.5 & 125.7 & & $125.8^{b}$ & $125.8^{c}$ & 125.9 & 125.9 \\
\hline $\mathrm{C}_{3}-\mathrm{C}_{2}-\mathrm{H}_{8} ; \mathrm{C}_{2}-\mathrm{C}_{3}-\mathrm{H}_{9}$ & 127.1 & 126.8 & & $126.9^{b}$ & $126.9^{c}$ & 126.9 & 126.9 \\
\hline $\mathrm{C}_{1}-\mathrm{N}_{5}-\mathrm{C}_{4}$ & 109.8 & 109.8 & & $109.7^{b}$ & $109.9^{c}$ & 109.8 & 109.8 \\
\hline $\mathrm{C}_{1}-\mathrm{N}_{5}-\mathrm{H}_{6} ; \mathrm{C}_{4}-\mathrm{N}_{5}-\mathrm{H}_{6}$ & 125.1 & 125.1 & & $125.2^{b}$ & $125.0^{c}$ & 125.0 & 125.1 \\
\hline inter-ring angle & & & 55.4 & & & 60.0 & 90.0 \\
\hline \multicolumn{8}{|c|}{ Rotational Constants /MHz } \\
\hline$A$ & 9130.610 & 9142.755 & 2972.900 & \multicolumn{2}{|c|}{2972.460} & 571.817 & 290.412 \\
\hline$B$ & 9001.343 & 9021.615 & 721.608 & \multicolumn{2}{|c|}{$\begin{array}{l}631.951 \\
594236\end{array}$} & 570.538 & 290.412 \\
\hline$C$ & 4532.083 & 4540.891 & 674.113 & \multicolumn{2}{|c|}{594.236} & 351.176 & 166.254 \\
\hline
\end{tabular}

${ }^{a}$ See Figure 1 for atom numbering. ${ }^{b} \mathrm{H}$-bond donor molecule. ${ }^{c} \mathrm{H}$-bond acceptor molecule. ${ }^{d}$ Adjacent rings. ${ }^{e}$ Opposed rings.

the H-bonded pyrrole units are $60.0^{\circ}$; the remaining two structures belong to the $\mathrm{C}_{s}$ (zigzag) and $C_{2 v}$ (distorted double T-shaped) symmetry point groups and have energies 13.3 and $17.9 \mathrm{~kJ} \mathrm{~mol}^{-1}$ higher than the most stable form, respectively (reported energies were corrected for zero-point vibrational energy; see Table 1). The tetramer may exist in four geometries, from which the most stable is the four-membered cyclic structure with $C_{4 h}$ symmetry (in this case, the inter-ring angle is $90^{\circ}$ ). The other forms (flaglike, zigzag, and distorted triple T-shaped) correspond to species that can be considered as being directly derived from the three trimers (cyclic, zigzag, and T-shaped, respectively) by addition of one pyrrole molecule (see Figure 1 for details). The relative energies of these higher energy tetramers are 10.6, 21.2, and $27.8 \mathrm{~kJ} \mathrm{~mol}^{-1}$, respectively.

For the dimer, the observation of a single minimum on the DFT potential energy surface is in consonance with the experimental evidence obtained by microwave spectroscopy. ${ }^{13}$ Careful inspection of the potential energy surface of the dimer was undertaken in order to evaluate the possibility of the existence of other structures corresponding to minima, with negative results (for example, the $\pi-\pi$ stacked structures converge to the T-shaped minimum, while the structure with the two $\mathrm{N}-\mathrm{H}$ groups antiparallel was found to correspond to a second-order saddle point, with an energy higher than the minimum by ca. $4 \mathrm{~kJ} \mathrm{~mol}^{-1}$ ). According to the calculations made in the present work, the dimer of pyrrole has a distance between the centers of mass of the monomers of $452.9 \mathrm{pm}$, in fairly good agreement with the value estimated from experiment $\left(411.6 \mathrm{pm}^{13}\right)$. The good general agreement between the experimental and calculated geometries of the dimer (Table 2) is also reflected in the relatively good reproduction by the calculations of the observed rotational constants for this species (calculated $A=2972.460, B=631.951, C=594.236 \mathrm{MHz}$, vs experimental $A=2972.900, B=721.608, C=674.113 \mathrm{MHz}$ ).

For both the trimer and tetramer of pyrrole, there are no available experimental data. In addition, these species were not 
the subject of any previous theoretical study. For these aggregates, the cyclic structures appear as the most stable species due to the fact that all units of pyrrole are interconnected and can establish as many H-bonds as possible both as donor or single-acceptor species. In all the other possible geometries, some of the units of pyrrole do not have their H-bond donor or single-acceptor capabilities satisfied (see Figure 1), thus justifying their higher relative energies.

The H-bond nature of the $\mathrm{NH} \cdots \pi$ intermolecular interaction in the aggregates of pyrrole is clearly revealed by the directional preference shown by this interaction, pointing to the middle of the $\mathrm{C}_{3}-\mathrm{C}_{4}$ bond of the acceptor molecule, as well as by the significantly larger $R(\mathrm{~N}-\mathrm{H})$ distance in the donor molecules when compared to the monomer. Figure 2 compares the individual $R(\mathrm{~N}-\mathrm{H})$ calculated distances for each studied species and correlates the $R(\mathrm{~N}-\mathrm{H}) \mathrm{H}$-bonded average distance with the calculated energy per H-bond (corrected by BSSE) for the different aggregates. From this figure, the following main conclusions can be drawn:

(a) The $R(\mathrm{~N}-\mathrm{H})$ distance in the hydrogen bonded acceptor molecules of the aggregates is slightly longer than that found in the monomer. When a molecule acts as a double H-bond acceptor, the $R(\mathrm{~N}-\mathrm{H})$ distance increases a little bit more than when it is a single H-bond acceptor. As mentioned before, the $\mathrm{H}$-bonds point to the $\mathrm{C}_{2}-\mathrm{C}_{3}$ bond of the acceptor molecule, being favored by an increased electron density in this bond. In turn, this increase of electron density in the $\mathrm{C}_{2}-\mathrm{C}_{3}$ bond requires that electrons be withdrawn from the opposite side of the molecule, including the $\mathrm{N}-\mathrm{H}$ bond, thus justifying the observations.

(b) In $\mathrm{H}$-bond donor molecules, the $R(\mathrm{~N}-\mathrm{H})$ distance is significantly longer than in the monomer. When a molecule acts simultaneously as an $\mathrm{N}-\mathrm{H}$ bond donor and acceptor, the $R(\mathrm{~N}-$ $\mathrm{H})$ distance attains its maximum value. This is particularly evident in the case of the cyclic trimer and tetramer, but does also occur for the central molecules of the zigzag trimer and tetramer and for the two molecules of the flaglike tetramer that are single $\mathrm{H}$-bond acceptor species. On the other hand, when two H-bonds are established to the same acceptor molecule, the $R(\mathrm{~N}-\mathrm{H})$ bond lengths of the donors assume values that are between those of the monomer and of a single $\mathrm{H}$-bonded donor molecule. Hence, on one side these results point to $\mathrm{H}$-bond cooperative effects in cyclic and chain (like zigzag) aggregates, leading to stronger H-bonds, while, on the other, they show that when two H-bonds are formed with the same acceptor molecule, the two bonds compete with each other, leading to weaker H-bonds. These conclusions are clearly revealed in the relative values of the calculated enthalpies of $\mathrm{H}$-bonding (per $\mathrm{H}$-bond) for the dimer $\left(-9.88 \mathrm{~kJ} \mathrm{~mol}^{-1}\right)$, which shall be here considered the reference value for an $\mathrm{H}$-bond in pyrrole selfaggregates, cyclic trimer $\left(-11.69 \mathrm{~kJ} \mathrm{~mol}^{-1}\right)$, which reflects the strengthening of the $\mathrm{H}$-bond due to cooperativity, and double T-shaped trimer $\left(-8.57 \mathrm{~kJ} \mathrm{~mol}^{-1}\right)$, where the two $\mathrm{H}$-bonds are formed with the same acceptor molecule and compete with each other (see Table 1).

(c) Cooperativity effects are particularly evident in the fact that the strength of the H-bonds, as revealed by both $R(\mathrm{~N}-\mathrm{H})$ distances (Figure 2) and energies of $\mathrm{H}$-bonding per $\mathrm{H}$-bond (see Table 1), is substantially higher in the cyclic tetramer than in the cyclic trimer (the same can be stated for the corresponding zigzag species). Indeed, the cooperative effect in pyrrole selfaggregates can just be described as the enhancement in the strength of the $\mathrm{H}$-bond interactions arising from the pyrrole units participating in more than one H-bond. Hence, the H-bond

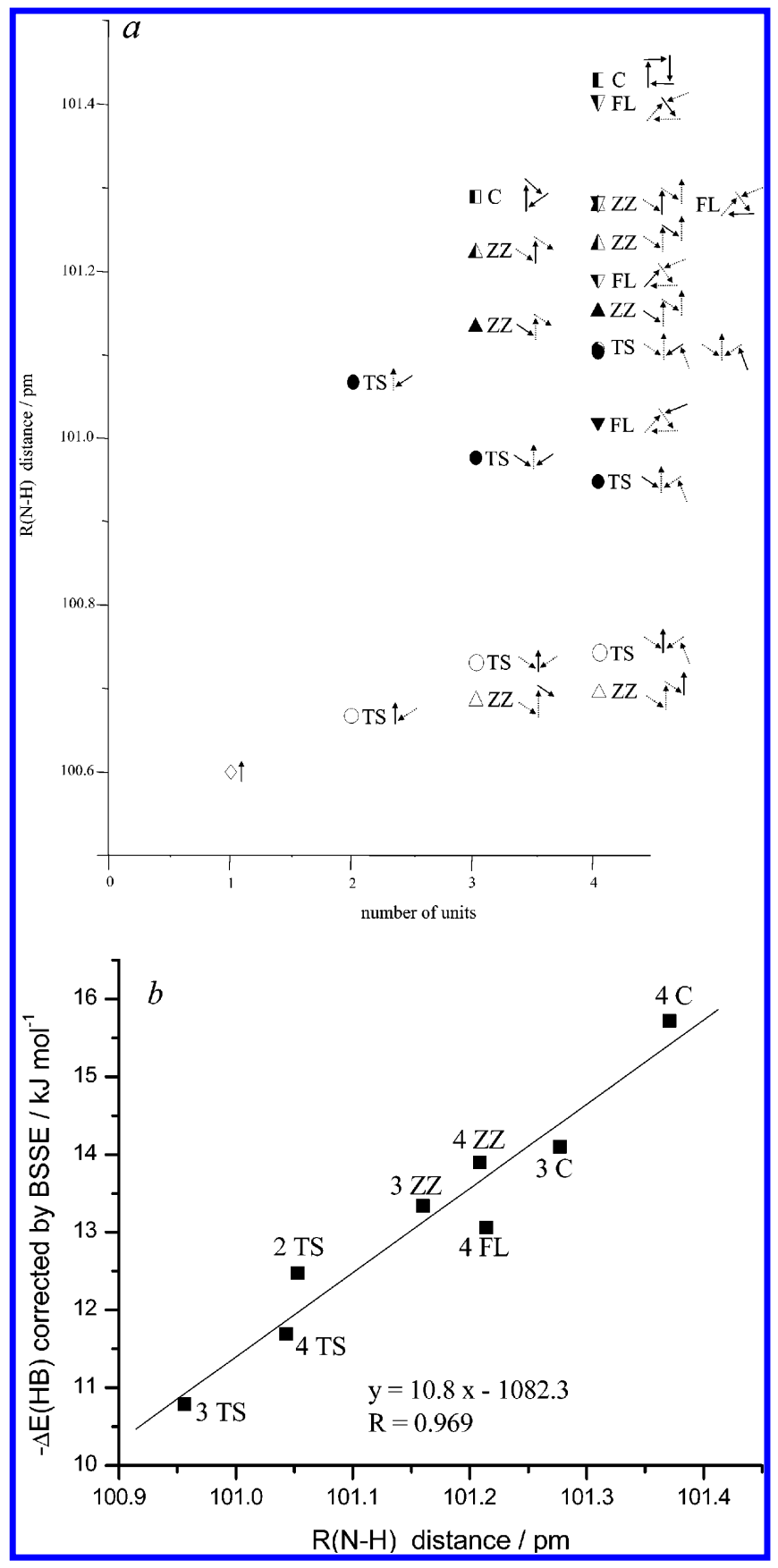

Figure 2. (a) $R(\mathrm{~N}-\mathrm{H})$ distance as a function of the cluster size. Squares represent cyclic structures (C); up triangles, zigzag structures (ZZ); circles, T-shaped structures (TS); down triangles, flaglike structures (FL). Filled symbols represent $\mathrm{H}$-donor units, nonfilled symbols represent $\mathrm{H}$-acceptor units, and half-filled symbols represent units acting as both acceptor and donor species. The specific unit(s) associated with a given distance value is(are) represented in the pictorial drawing of the molecular aggregates by the solid arrow(s). In each unit, the $\mathrm{N}-\mathrm{H}$ group is indicated by the end of the arrow. (b) Correlation between $-\Delta E(\mathrm{HB})$ (including BSSE correction) and the $R(\mathrm{~N}-\mathrm{H})$ distance for all the structures analyzed $(\mathrm{C}=$ cyclic, $\mathrm{TS}=\mathrm{T}$-shaped, $\mathrm{ZZ}=$ zigzag, $\mathrm{FL}=$ flaglike). The numbers in the symbol legend represent the number of units taking part of the aggregate.

cooperativity can be quantitatively measured from the DFTcalculated energies per hydrogen bond, which are obtained by dividing the binding energy (the difference between the energy of a cluster and the total energy of their constituting units) by the number of hydrogen bonds present in the cluster (Table 1). The deviation of the average bond energy obtained in this way from that calculated for the dimer (which has only an H-bond 


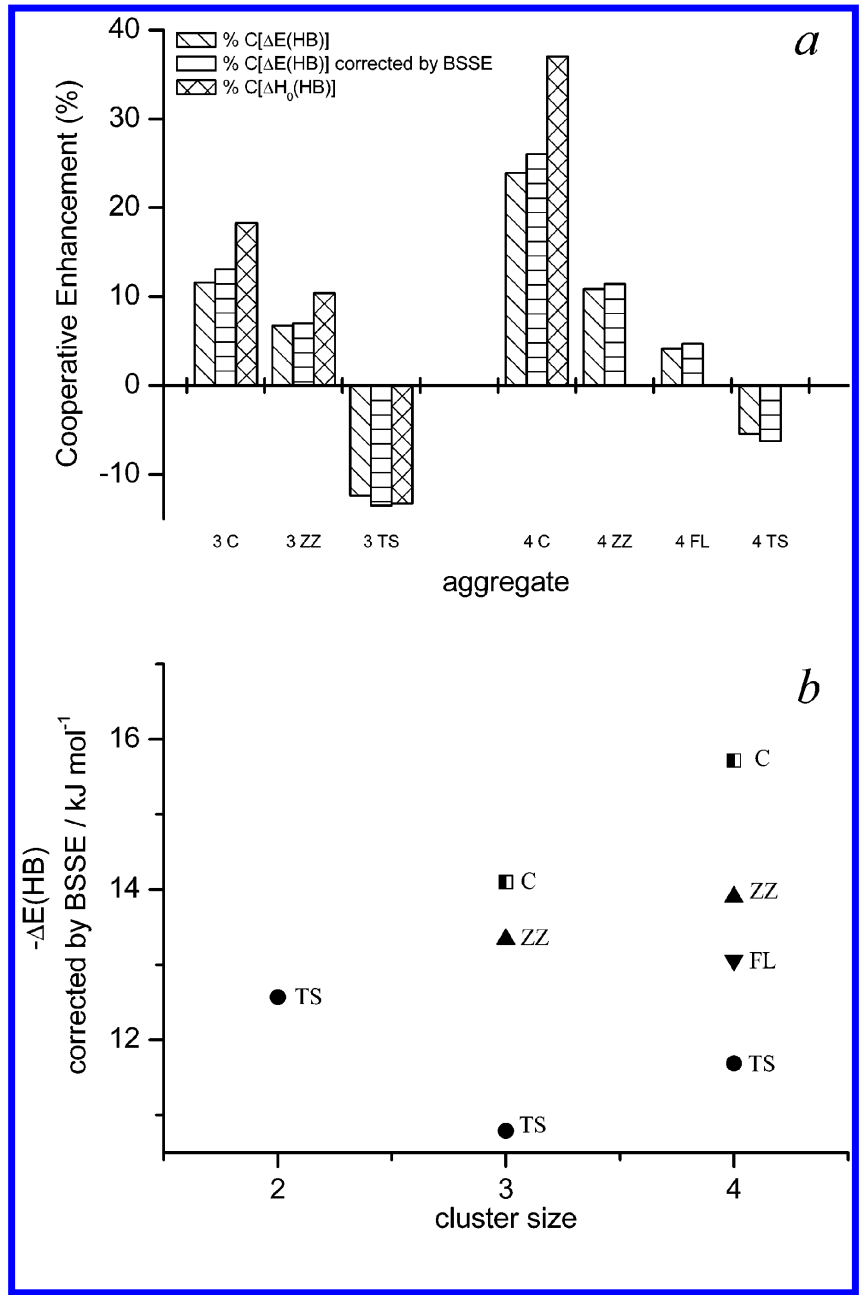

Figure 3. (a) Plot showing the H-bond cooperative enhancement in the self-aggregates of pyrrole of three and four units (see Table 1 for details). (b) Correlation between $-\Delta E(\mathrm{HB})$ (including BSSE correction) and the cluster size.

and, consequently, has a binding energy that is coincident with the energy per H-bond) indicates the extent of H-bond cooperativity or $\mathrm{H}$-bond cooperative enhancement $(C$, expressed in percentage in Table 1). Figure 3 displays graphically the relevant data to look at the cooperative enhancement in the different aggregates studied. As could be expected, cooperativity is more important for cyclic aggregates, and among them, it increases with the number of units. The cooperative enhancement (estimated on the basis of $\Delta H_{\mathrm{o}}(\mathrm{HB})$; see Table 1 and Figure 3a) for the cyclic tetramer is as large as $37 \%$, i.e., nearly twice the equivalent value obtained for the cyclic trimer. Note that zero-point vibrational energy contributions are relevant to cooperativity enhancement values reported in Table 1 (and Figure 3a), while BSSE corrections were not found to be so important (testifying the adequacy of the basis set used in the calculations). Zigzag aggregates do also exhibit important $\mathrm{H}$-bond cooperative enhancements, while in the T-shaped structures the cooperativity does not exist at all. On the contrary, in the T-shaped aggregates $\mathrm{H}$-bonding is dominated by the competitive effect of the H-bonds established with the same acceptor molecule that considerably weakens the interaction so that, on average, the H-bond strength is lower than in the dimer (see Figure $3 \mathrm{~b}$ ) and the $\% C$ values are negative. The flaglike tetramer shows a small global cooperative enhancement, as a result of the opposite effects of the cooperativity associated with the $\mathrm{H}$-bonds involving single $\mathrm{H}$-bond acceptor molecules and

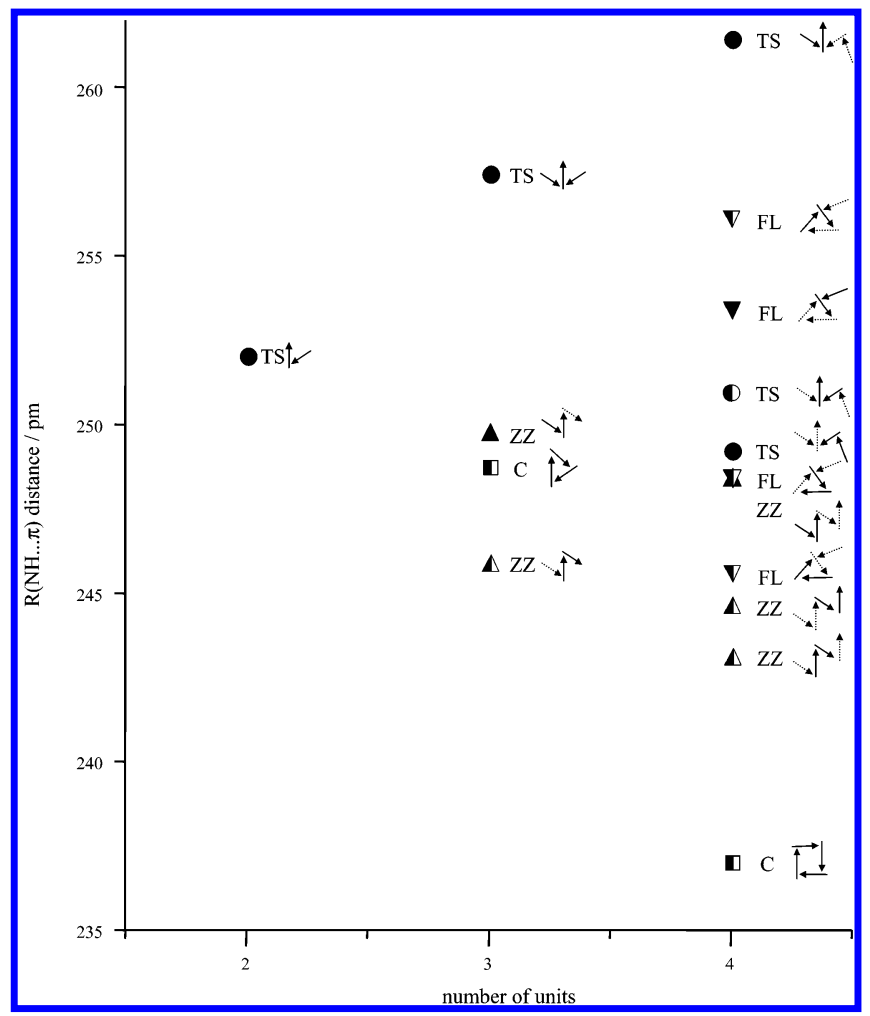

Figure 4. $R(\mathrm{NH} \cdots \pi)$ distance as a function of the cluster size. Symbols follow the same criterion as in Figure 2a. The specific units associated with a given distance value (both donor and acceptor molecule) are represented in the pictorial drawing of the molecular aggregates by solid arrows. In each unit, the $\mathrm{N}-\mathrm{H}$ group is indicated by the end of the arrow.

the weakening contribution associated with the H-bonds involving the same acceptor molecule.

(d) Finally, the close relationship between the $R(\mathrm{~N}-\mathrm{H})$ distances and the strengths of the H-bonds in the different species are also clearly shown in the correlation shown in Figure $2 \mathrm{~b}$ between the average value of the $R(\mathrm{~N}-\mathrm{H}) \mathrm{H}$-bonded distances in a given aggregate and the corresponding calculated $\mathrm{H}$-bond energy per H-bond (see also Table 1).

Besides $R(\mathrm{~N}-\mathrm{H})$, other structural parameters, such as the $R(\mathrm{NH} \cdots \pi)$ hydrogen bond distance, can also be used as indicators of the strength of the intermolecular H-bonds in pyrrole aggregates (Figure 4). As expected, among the species studied, the $R(\mathrm{NH} \cdots \pi)$ attains its minimum value for the cyclic tetramer $(237 \mathrm{pm})$. In the case of all H-bonded molecules acting simultaneously as acceptors and donors to a molecule that accepts a single H-bond, $R(\mathrm{NH} \cdots \pi)$ stays within the $243-249$ pm range (see Figure 4a), whereas this distance is between 249 and $254 \mathrm{pm}$ for molecules that act only as H-bond donors. Finally, also in consonance with the results obtained from the analysis of the $R(\mathrm{~N}-\mathrm{H})$ bond length, the $R(\mathrm{NH} \cdots \pi)$ hydrogen bond distances in the molecules connected to an acceptor which is involved in two hydrogen bonds are (with a single exception) longer than $255 \mathrm{pm}$, clearly revealing once again the weaker character of the $\mathrm{H}$-bond interaction in these cases.

$R(\mathrm{NH} \cdots \pi)$ can also be used to compare the H-bond strength in the pyrrole dimer and other $\mathrm{H}$-bonded dimers involving $\mathrm{NH} \cdots \pi$ hydrogen bonding. The $R(\mathrm{NH} \cdots \pi)$ distance in the most stable pyrrole-indole, indole-indole and indole-pyrrole dimers (first molecule corresponds to the donor molecule) were found to be $256.4,271.2$, and $252.1 \mathrm{pm}$, respectively, ${ }^{25,26}$ thus indicating that the $\mathrm{H}$-bond is stronger in the pyrrole dimer $[R(\mathrm{NH} \cdots \pi)$ equal to $252.0 \mathrm{pm}$ which is the DFT(B3LYP)/ 


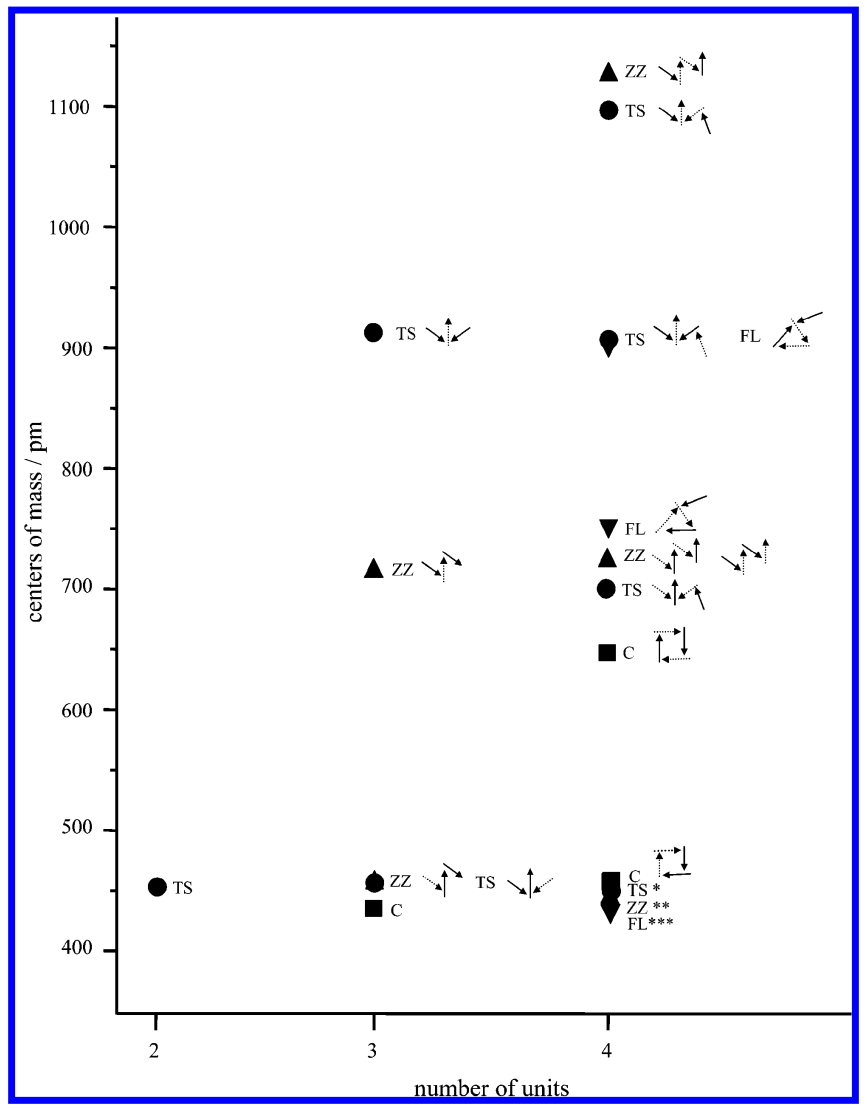

Figure 5. Distances among the centers of mass as a function of the cluster size. Symbols follow the same criterion as in Figures $2 \mathrm{a}$ and 4. The specific units associated with a given distance value are represented in the pictorial drawing of the molecular aggregates by solid arrows. In each unit, the $\mathrm{N}-\mathrm{H}$ group is indicated by the end of the arrow. *TS: all distances between centers of mass of vicinal molecules stay within the 448-459 pm range. **ZZ: all distances between centers of mass of vicinal molecules stay within the $454-460 \mathrm{pm}$ range. ***FL: all distances between centers of mass of vicinal molecules stay within the $430-446 \mathrm{pm}$ range.

$6-311++\mathrm{G}(\mathrm{d}, \mathrm{p})$-calculated value obtained in this study. The $R(\mathrm{NH} \cdots \pi)$ distance that has been obtained at the same level of theory as the above-mentioned distances for the other dimers $[\mathrm{DFT}(\mathrm{B} 3 \mathrm{LYP}) / 6-31++\mathrm{G}(\mathrm{d}, \mathrm{p})]$ is $247.5 \mathrm{pm},{ }^{24}$ i.e., still a bit shorter than the value obtained in the present study.] Interestingly, the $\mathrm{H}$-bond is stronger when pyrrole acts as the acceptor and indole as the donor, thus correlating well with the $\mathrm{p} K_{\mathrm{a}}$ 's of the donor (for pyrrole, the $\mathrm{p} K_{\mathrm{a}}$ is 23.0 , while for indole it is $21.0^{74}$ ) and indicating a better ability of pyrrole to act as an H-bond $\pi$ acceptor when compared with indole.

The distances between the centers of mass of the molecules constituting the different clusters (Figure 5) can also provide useful information about geometrical preferences of the monomeric units in the different aggregates. The main conclusion that can be extracted from Figure 5 is that in all aggregates the distances between the centers of mass between neighboring molecules are identical to that found in the dimer (452.9 pm), ranging from 430 to $460 \mathrm{pm}$, while for molecules separated by one unit the distances spray through a larger range of values (650-940 pm). In the last case, the largest distances occur for $\mathrm{H}$-bond donor molecules bound to a common acceptor molecule, as a consequence of both the nearly antiparallel alignment of the molecules and the weakest H-bonds found in these cases.

Vibrational Spectra for the Matrix-Isolated Compound. As mentioned in the Introduction, the high tendency of pyrrole to aggregate is the main difficulty for its isolation in a low- temperature inert matrix. This inconvenience was solved by using the doubly thermostatable cell developed in our laboratory, ${ }^{62}$ with a $2: 1$ water/acetone mixture as substance cooler and the valve nozzle kept at room temperature. Figure 6 shows the IR spectra obtained for the matrix-isolated compound in both argon and xenon matrixes (deposition temperature: $9 \mathrm{~K}$ ), obtained using this procedure. The DFT-calculated spectrum of the monomer is also shown in Figure 6 for comparison.

The 24 vibrations of pyrrole $\left(C_{2 v}\right.$ point group) span the irreducible representation $9 \mathrm{~A}_{1}+3 \mathrm{~A}_{2}+8 \mathrm{~B}_{1}+4 \mathrm{~B}_{2}$, with all but the three $\mathrm{A}_{2}$ modes being active in the infrared and all modes being active in Raman. Since all bands are expected to occur above $450 \mathrm{~cm}^{-1}$, all 21 IR active modes could in principle be observed under the experimental conditions used in this study.

As can be observed in Figure 6, the calculated spectrum for the monomer fits nicely the most prominent bands in the experimental spectra. The assignment of the experimental spectra is presented in Table 3, where the approximate descriptions of vibrational modes adopted are similar to those previously used by Xie et al. ${ }^{37}$

The spectra obtained at $9 \mathrm{~K}$ in both rare gases are dominated by three very strong bands at ca. 3520, 720, and $480 \mathrm{~cm}^{-1}$, which are assigned to the $\nu \mathrm{N}-\mathrm{H}, \gamma \mathrm{C}-\mathrm{H}$ sym, and $\gamma \mathrm{N}-\mathrm{H}$ vibrations. Both $\nu \mathrm{N}-\mathrm{H}$ and $\gamma \mathrm{N}-\mathrm{H}$ are well-localized vibrations that have been shown to be quite sensitive to H-bonding. ${ }^{75}$ The $\gamma \mathrm{C}-\mathrm{H}$ out-of-plane ring modes are also well-known to be sensitive probes of intermolecular interactions and packing. ${ }^{76}$ These three spectral regions will then be considered in deeper detail later on in this paper to investigate pyrrole selfaggregation. The $\delta \mathrm{N}-\mathrm{H}$ in-plane bending is considerably more delocalized than both $\nu \mathrm{N}-\mathrm{H}$ and $\gamma \mathrm{N}-\mathrm{H},{ }^{52}$ appearing at ca. 1135 $\mathrm{cm}^{-1}$. The assignments for the remaining vibrations closely follow those reported previously for the compound in the gaseous phase ${ }^{48}$ and are also in good agreement with the theoretical predictions. Despite this, a few comments shall be made here:

(a) As previously found for the compound in the gaseous phase, ${ }^{48}$ a large number of overtones and combination bands were observed in the spectra of the matrix-isolated molecule. It shall be stressed that our observations fully confirm the assignments of these bands made by Klotz et al. ${ }^{48}$ in particular, all gas-phase bands assigned by those authors to subtractive combination bands and hot bands could not be observed in the matrix-isolated compound, as expected.

(b) When compared with the spectra obtained in argon matrixes, the spectra of the compound isolated in xenon exhibit more pronounced band splitting due to matrix-site effects and show systematically broader bands (see Figure 6 and Table 3 ). These results can be correlated with a larger inhomogeneity of the local environment around pyrrole molecules in the xenon matrixes and do also seem to indicate that the pyrrole molecules perturb to a larger extent the packing of xenon atoms, compared to argon.

(c) The structured band observed around $980 \mathrm{~cm}^{-1}$ (in argon) is assigned to the first overtone of the $\gamma \mathrm{N}-\mathrm{H}$ vibration, in all probability taking part in a Fermi resonance interaction with the $\delta \mathrm{C}-\mathrm{H}$ asymmetric mode which also gives rise to the band observed at $1017.2 \mathrm{~cm}^{-1}$. Compared to the gas phase, the $\gamma \mathrm{N}-\mathrm{H}$ mode appears blue shifted by ca. $10 \mathrm{~cm}^{-1}$ in the argon matrix spectrum. The observed shift in the fundamental mode thus correlates well with the frequency shift found in the overtone upon going from the gas-phase to the matrix isolation spectra (ca. $20 \mathrm{~cm}^{-1}$ ). In addition, also in agreement with the gas-phase results, ${ }^{48}$ the $\gamma \mathrm{N}-\mathrm{H}$ mode is now shown to present a consider- 


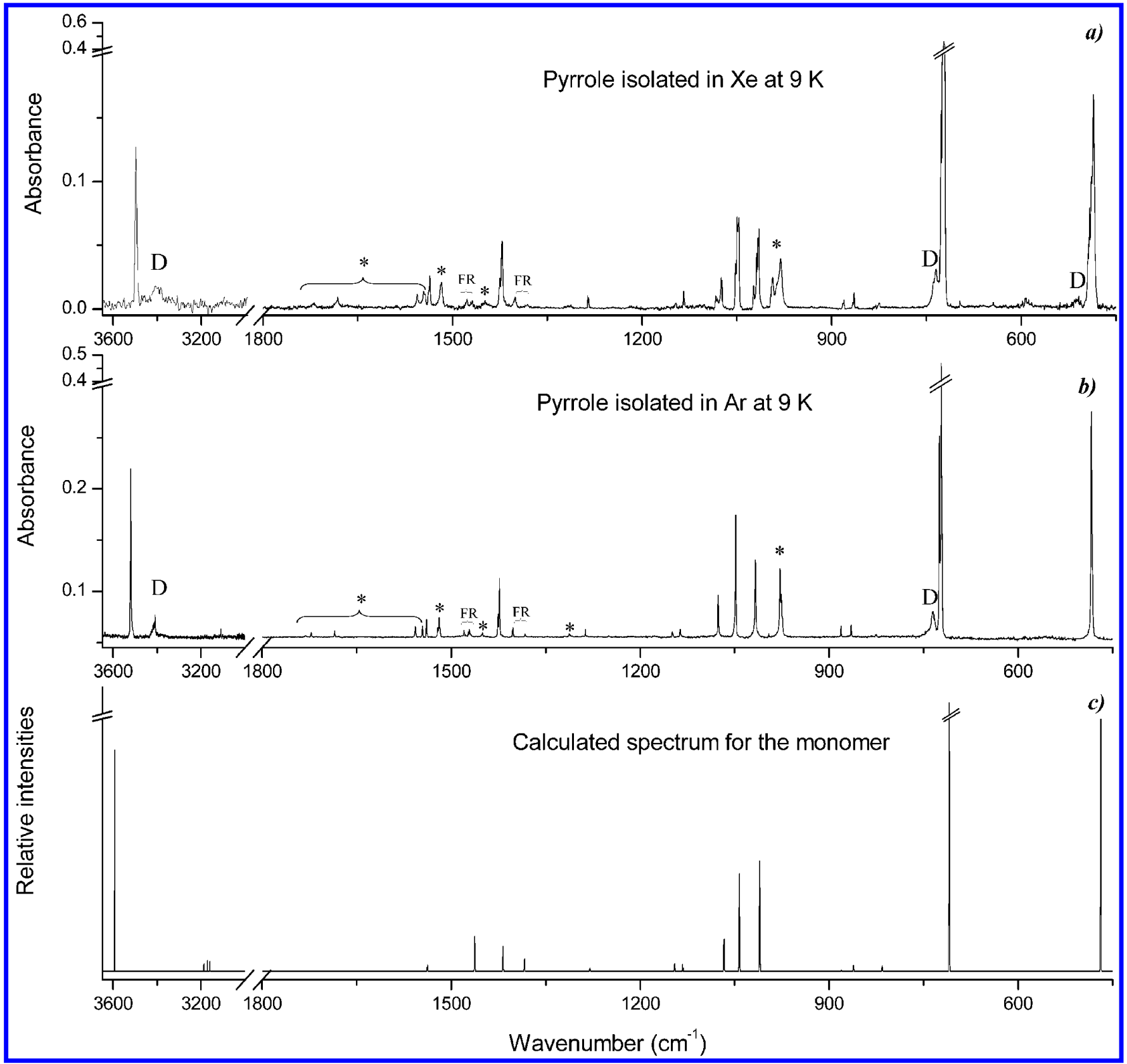

Figure 6. Infrared spectra of pyrrole: (a) isolated in a xenon matrix $(T=9 \mathrm{~K})$; (b) isolated in an argon matrix $(T=9 \mathrm{~K})$; (c) DFT(B3LYP)/6$311++\mathrm{G}(\mathrm{d}, \mathrm{p})$-calculated spectrum for the monomer. Bands due to traces of dimers are indicated by the letter D. FR refers to Fermi resonance doublets. Bands corresponding to overtones and combination bands are marked with an asterisk (*). Note the break in the vertical scales.

able negative anharmonicity also in the case of the matrixisolated compound.

The change in the matrix concentration and annealing of the matrixes yield qualitatively similar results, with bands due to aggregates of pyrrole becoming noticeable in the spectra. Figure 7 shows the dependence with the concentration of the matrix of the most relevant spectral regions (results obtained in argon were selected for presentation due to the fact that the bands are narrower than in xenon and, as referred to above, less important site splitting occurs). In this figure, the calculated spectra of pyrrole and of its self-aggregates are shown for comparison (for both the trimer and tetramer only the spectra of the more stable cyclic structures are presented, since the relative energies of the other aggregates are high enough to prevent its population from being comparatively important in a low-temperature matrix).

In the $v \mathrm{~N}-\mathrm{H}$ stretching region (Figure 7a), the spectrum of the less-concentrated matrix shows already traces of the dimer, represented by the shoulder at ca. $3510 \mathrm{~cm}^{-1}$ and features around $3410-3420 \mathrm{~cm}^{-1}$, which are due to the $v \mathrm{~N}-\mathrm{H}$ stretching vibrations of the "free" and $\mathrm{H}$-bonded $\mathrm{N}-\mathrm{H}$ groups, belonging to the H-bond acceptor and donor molecule, respectively. At higher concentrations, bands due to higher aggregates appear in the spectra at frequencies lower than those corresponding to the dimer. The slightly lower $v \mathrm{~N}-\mathrm{H}$ stretching frequency observed for the acceptor molecule in the dimer when compared with the monomer is in consonance with the structural results that indicated that the participation of a pyrrole molecule as an $\mathrm{H}$-bond acceptor decreases the electron density of the $\mathrm{N}-\mathrm{H}$ bond, increasing the $\mathrm{N}-\mathrm{H}$ bond length and reducing its stretching frequency. On the other hand, the H-bond enthalpy in the dimer can be estimated from the difference in the frequencies of the monomer and $\mathrm{H}$-bond donor molecule in the dimer using the Iogansen's correlation: ${ }^{77}(\Delta H)^{2}=1.92(\Delta v-$ 40), where $\Delta H$ is expressed in $\mathrm{kJ} \mathrm{mol}^{-1}$. The value obtained from this empirical correlation, $-11.45 \mathrm{~kJ} \mathrm{~mol}^{-1}$, correlates well 
TABLE 3: Experimental and Calculated [DFT (B3LYP)/6-311++G(d,p)] Wavenumbers and Intensities for the Monomer of Pyrrole $^{a}$

\begin{tabular}{|c|c|c|c|c|c|c|c|c|}
\hline \multirow{2}{*}{$\begin{array}{c}\text { approximate } \\
\text { description }\end{array}$} & \multirow[b]{2}{*}{ symmetry } & \multirow[b]{2}{*}{ vapor $^{48}$} & \multicolumn{2}{|c|}{ experimental (Ar matrix) } & \multicolumn{2}{|c|}{ experimental (Xe matrix) } & \multicolumn{2}{|c|}{ calculated } \\
\hline & & & wavenumber & intensity & wavenumber & intensity & wavenumber $^{b}$ & intensity \\
\hline$v \mathrm{~N}-\mathrm{H}$ & $\mathrm{A}_{1}$ & 3530.6 & $3523.0 / 3520.8$ & $\mathrm{~S} / \mathrm{S}$ & $3504.6 / 3500.6 / 3499.1$ & $\mathrm{~S} / \mathrm{S} / \mathrm{S}$ & 3592.8 & 68.3 \\
\hline$v \mathrm{C}-\mathrm{H}_{\mathrm{sym}}$ & $\mathrm{A}_{1}$ & n.o. & n.o & & & & 3192.2 & $<0.1$ \\
\hline$v \mathrm{C}-\mathrm{H}_{\text {as }}$ & $\mathrm{B}_{1}$ & 3143.0 & $\sim 3134.8$ & $\mathrm{w}$ & & & 3186.8 & 2.4 \\
\hline$v \mathrm{C}-\mathrm{H}_{\mathrm{sym}}^{\mathrm{as}}$ & $\mathrm{A}_{1}$ & 3127.8 & $\sim 3119.4$ & w & & & 3170.7 & 3.3 \\
\hline$\nu \mathrm{C}-\mathrm{H}_{\text {as }}$ & $\mathrm{B}_{1}$ & 3118.4 & 3109.8 & $\mathrm{w}$ & & & 3159.4 & 3.0 \\
\hline$\gamma \mathrm{C}-\mathrm{H}\left(\mathrm{A}_{2}\right)+\delta \mathrm{C}-\mathrm{H}\left(\mathrm{B}_{1}\right)$ & $\mathrm{B}_{2}$ & 1740.7 & 1730.9 & $\mathrm{w}$ & & & & \\
\hline $2 \times \gamma \mathrm{C}-\mathrm{H}\left(\mathrm{A}_{2}\right)$ & $\mathrm{A}_{1}$ & 1726.4 & 1721.9 & w & 1719.1 & $\mathrm{w}$ & & \\
\hline$\gamma \mathrm{C}-\mathrm{H}\left(\mathrm{A}_{2}\right)+\gamma \mathrm{C}-\mathrm{H}\left(\mathrm{B}_{2}\right)$ & $\mathrm{B}_{1}$ & 1688.6 & 1684.8 & $\mathrm{w}$ & 1681.8 & $\mathrm{w}$ & & \\
\hline$\gamma \mathrm{C}-\mathrm{H}\left(\mathrm{A}_{2}\right)+\gamma \mathrm{C}-\mathrm{H}\left(\mathrm{A}_{2}\right)$ & $\mathrm{A}_{1}$ & 1556.8 & 1556.8 & $\mathrm{w}$ & 1555.9 & $\mathrm{w}$ & & \\
\hline$\gamma \mathrm{C}-\mathrm{H}\left(\mathrm{B}_{2}\right)+\gamma \mathrm{C}-\mathrm{H}\left(\mathrm{B}_{2}\right)$ or & $\mathrm{A}_{1}$ & & & & & & & \\
\hline$\delta \mathrm{C}-\mathrm{H}\left(\mathrm{A}_{1}\right)+\gamma \mathrm{N}-\mathrm{H}\left(\mathrm{B}_{2}\right)$ & $\mathrm{B}_{2}$ & 1547.1 & 1545.6 & $\mathrm{w}$ & $1545.7 / 1543.3$ & $\mathrm{w} / \mathrm{w}$ & & \\
\hline$\nu \mathrm{C}=\mathrm{C}_{\text {as }}$ & $\mathrm{B}_{1}$ & 1542.0 & 1539.1 & $\mathrm{w}$ & $1537.8 / 1536.1$ & $\mathrm{w} / \mathrm{w}$ & 1536.8 & 2.1 \\
\hline$\gamma \mathrm{C}-\mathrm{H}\left(\mathrm{A}_{2}\right)+\gamma \mathrm{C}-\mathrm{H}\left(\mathrm{B}_{2}\right)$ & $\mathrm{B}_{1}$ & 1518.2 & $1521.0 / 1518.8 / 1517.6$ & $\mathrm{w} / \mathrm{w} / \mathrm{w}$ & 1517.3 & w & & \\
\hline$\delta \mathrm{C}-\mathrm{N}-\mathrm{C}\left(\mathrm{A}_{1}\right)+\tau \operatorname{ring}{ }_{\text {sym }}\left(\mathrm{B}_{2}\right)$ & $\mathrm{B}_{2}$ & 1504.6 & 1505.7 & w & & & & \\
\hline $\begin{array}{l}{\left[\gamma \mathrm{C}-\mathrm{H}\left(\mathrm{A}_{2}\right)+\tau \text { ring as }\left(\mathrm{A}_{2}\right)\right] /} \\
\nu \mathrm{C}=\mathrm{C}_{\mathrm{sym}} \mathrm{FR}\end{array}$ & $\mathrm{A}_{1}$ & 1480.5 & 1479.5 & $\mathrm{w}$ & 1477.3 & w & & \\
\hline $\begin{array}{l}\nu \mathrm{C}=\mathrm{C}_{\mathrm{sym} /} \\
{\left[\gamma \mathrm{C}-\mathrm{H}\left(\mathrm{A}_{2}\right)+\tau \operatorname{ring}_{\text {as }}\left(\mathrm{A}_{2}\right)\right] \mathrm{FR}}\end{array}$ & $\mathrm{A}_{1}$ & 1471.7 & $1472.7 / 1471.0 / 1469.8$ & $\mathrm{w} / \mathrm{w} / \mathrm{w}$ & $1471.1 / 1468.8$ & $\mathrm{w} / \mathrm{w}$ & 1461.8 & 10.9 \\
\hline $2 \times \gamma \mathrm{C}-\mathrm{H}\left(\mathrm{B}_{2}\right)$ & $\mathrm{A}_{1}$ & n.o. & 1450.2 & w & $\sim 1448.7$ & w & & \\
\hline$\nu \mathrm{C}-\mathrm{N}_{\text {as }}$ & $\mathrm{B}_{1}$ & 1424.2 & $1425.8 / 1423.5$ & $\mathrm{~m} / \mathrm{m}$ & $1425.0 / 1421.3$ & $\mathrm{~m} / \mathrm{m}$ & 1416.8 & 7.8 \\
\hline $\begin{array}{l}v \mathrm{C}-\mathrm{C}\left(\mathrm{A}_{1}\right) / \\
2 \times \gamma \mathrm{C}-\mathrm{H}\left(\mathrm{A}_{2}\right) \mathrm{FR}\end{array}$ & $\mathrm{A}_{1}$ & 1400.8 & 1401.9 & w & 1400.8 & $\mathrm{w}$ & 1382.8 & 3.8 \\
\hline $\begin{array}{l}2 \times \gamma \mathrm{C}-\mathrm{H}\left(\mathrm{A}_{2}\right) / \\
v \mathrm{C}-\mathrm{C}\left(\mathrm{A}_{1}\right) \mathrm{FR}\end{array}$ & $\mathrm{A}_{1}$ & 1380.6 & 1382.6 & w & 1381.1 & w & & \\
\hline$\tau$ ring as $\left(\mathrm{A}_{2}\right)+\gamma \mathrm{C}-\mathrm{H}\left(\mathrm{A}_{2}\right)$ & $\mathrm{A}_{1}$ & 1304.0 & 1312.3 & $\mathrm{w}$ & 1312.7 & $\mathrm{w}$ & & \\
\hline$\delta \mathrm{C}-\mathrm{H}_{\text {as }}$ & $\mathrm{B}_{1}$ & 1288.4 & 1286.6 & $\mathrm{w}$ & $1286.0 / 1284.4$ & $w / w$ & 1279.1 & 0.9 \\
\hline breathing & $\mathrm{A}_{1}$ & 1148.1 & 1149.0 & $\mathrm{w}$ & 1146.6 & w & 1145.0 & 2.3 \\
\hline$\delta \mathrm{N}-\mathrm{H}_{\mathrm{ip}}$ & $\mathrm{B}_{1}$ & 1134.1 & 1136.7 & w & 1133.9 & w & 1132.1 & 2.3 \\
\hline$\delta \mathrm{C}-\mathrm{H}_{\mathrm{sym}}$ & $\mathrm{A}_{1}$ & 1074.4 & 1076.2 & $\mathrm{~m}$ & 1074.6 & $\mathrm{~m}$ & 1066.3 & 10.0 \\
\hline$\delta \mathrm{C}-\mathrm{H}_{\text {as }}$ & $\mathrm{B}_{1}$ & 1049.2 & 1048.5 & $\mathrm{~m}$ & $1047.7 / 1046.7$ & $\mathrm{~m} / \mathrm{m}$ & 1042.0 & 30.1 \\
\hline $\begin{array}{l}\delta \mathrm{C}-\mathrm{H}_{\text {sym }} / \\
2 \times \gamma \mathrm{N}-\mathrm{H}\left(\mathrm{B}_{2}\right) \mathrm{FR}\end{array}$ & $\mathrm{A}_{1}$ & 1017.2 & 1017.2 & $\mathrm{~m}$ & $1023.5 / 1018.9 / 1016.4$ & $\mathrm{~m} / \mathrm{m} / \mathrm{m}$ & 1009.7 & 34.1 \\
\hline $\begin{array}{l}2 \times \gamma \mathrm{N}-\mathrm{H}\left(\mathrm{B}_{2}\right) / \\
\delta \mathrm{C}-\mathrm{H}_{\mathrm{sym}}\left(\mathrm{A}_{1}\right) \mathrm{FR}\end{array}$ & $\mathrm{A}_{1}$ & 962.1 & 995.9/977.9/976.0/974.3 & $\mathrm{w} / \mathrm{w} / \mathrm{w} / \mathrm{w}$ & $993.0 / 980.7$ & $\mathrm{~m} / \mathrm{m}$ & & \\
\hline$\delta \mathrm{C}-\mathrm{N}-\mathrm{C}$ & $\mathrm{A}_{1}$ & 881.5 & 881.0 & $\mathrm{w}$ & 880.2 & $\mathrm{w}$ & 880.5 & 0.4 \\
\hline$\delta \mathrm{C}-\mathrm{C}-\mathrm{C}_{\text {as }}$ & $\mathrm{B}_{1}$ & 865.6 & 865.3 & $\mathrm{w}$ & 864.4 & w & 860.8 & 1.8 \\
\hline$\gamma \mathrm{C}-\mathrm{H}_{\text {as }}$ & $\mathrm{A}_{2}$ & $(864.1)^{c}$ & n.o. & & n.o. & & 864.3 & 0.0 \\
\hline$\gamma \mathrm{C}-\mathrm{H}_{\mathrm{sym}}$ & $\mathrm{B}_{2}$ & 826.7 & $826.6 / 825.0$ & $\mathrm{w} / \mathrm{w}$ & 824.9 & $\mathrm{w}$ & 815.5 & 1.6 \\
\hline$\gamma \mathrm{C}-\mathrm{H}_{\mathrm{sym}}$ & $\mathrm{B}_{2}$ & 722.0 & $725.4 / 721.9$ & $\mathrm{~S} / \mathrm{S}$ & $722.3 / 721.3$ & $\mathrm{~S} / \mathrm{S}$ & 709.3 & 169.7 \\
\hline$\gamma \mathrm{C}-\mathrm{H}_{\text {as }}$ & $\mathrm{A}_{2}$ & $(692.2)^{c}$ & n.o. & & n.o. & & 673.2 & 0.0 \\
\hline$\tau$ ring $_{\text {sym }}$ & $\mathrm{B}_{2}$ & n.o. & n.o. & & n.o. & & 622.1 & $<0.1$ \\
\hline$\tau$ ring as & $\mathrm{A}_{2}$ & $(613.6)^{c}$ & n.o. & & n.o. & & 613.5 & 0.0 \\
\hline$\gamma \mathrm{N}-\mathrm{H}$ & $\mathrm{B}_{2}$ & 474.4 & $483.7 / 483.0 / 481.9$ & $\mathrm{~S} / \mathrm{S} / \mathrm{S}$ & 493.6/491.6/488.5/485.6/483.4 & $\mathrm{S} / \mathrm{S} / \mathrm{S} / \mathrm{S} / \mathrm{S}$ & 468.8 & 78.9 \\
\hline
\end{tabular}

${ }^{a}$ Wavenumbers in $\mathrm{cm}^{-1}$, calculated intensities in $\mathrm{km} \mathrm{mol}^{-1} . \nu$, stretching; $\delta$, in-plane bending; $\gamma$, out-of-plane bending; $\tau$, torsion; sym, symmetric; as, asymmetric; ip, in-plane; S, strong; m, medium; w, weak; FR, Fermi resonance; n.o., not observed. ${ }^{b}$ Scaled by $0.978 .{ }^{c}$ Determined from difference bands. ${ }^{48}$

with the theoretical value presented in Table $1\left(9.88 \mathrm{~kJ} \mathrm{~mol}^{-1}\right)$. For the trimer and tetramer, the correlation yields $\Delta H$ equal to -12.84 and $-14.12 \mathrm{~kJ} \mathrm{~mol}^{-1}$, respectively, also in good agreement with the results predicted by the theoretical calculations presented in Table $1\left(-11.69\right.$ and $\left.-13.54 \mathrm{~kJ} \mathrm{~mol}^{-1}\right)$.

In the $1300-1100 \mathrm{~cm}^{-1}$ spectral region the monomer gives rise to three spectral features, the $\delta \mathrm{C}-\mathrm{H}$ asymmetric bending mode where all $\mathrm{C}-\mathrm{H}$ bonds bend in the same direction, the $\delta \mathrm{N}-\mathrm{H}$ in-plane bending vibration, and the breathing mode, which appear at $1286.6,1149.0$, and $1136.7 \mathrm{~cm}^{-1}$, respectively. In the spectra of the concentrated matrixes, the bands due to the aggregates emerged: the $\delta \mathrm{C}-\mathrm{H}$ mode as a new band at $1267 \mathrm{~cm}^{-1}$ that, in consonance with the theoretical predictions shall contain contributions from dimer, trimer, and tetramer, and the two lower frequency modes as overlapped bands covering the spectral range of $1148-1140 \mathrm{~cm}^{-1}$ (see Figure $7 \mathrm{~b}$ and Table 4). It is interesting to note that the calculations do not predict any substantial red shift in the frequency of the $\delta \mathrm{C}-\mathrm{H}$ mode upon aggregation, while the experimental results show a red shift of ca. $20 \mathrm{~cm}^{-1}$, indicating that this vibration seem to be particularly sensitive to effects of interactions with the matrix. On the other hand, the small observed shifts upon aggregation in both the breathing and $\delta \mathrm{N}-\mathrm{H}$ in-plane modes are well predicted by the calculations.
The good prediction of the shifts due to aggregation by the theoretical calculations is particularly noticeable in the case of the modes appearing in the $1100-1000 \mathrm{~cm}^{-1}$ spectral range (see Figure $7 \mathrm{c}$ ). All three vibrations absorbing in this region are $\delta \mathrm{C}-\mathrm{H}$ bending modes, and the calculations predicted that the two higher frequency bands should blue shift slightly, while the low-frequency mode should experience a very small red shift. It is noteworthy that the experimental observations fully confirm these predictions.

The expected frequency changes upon aggregation are predicted to be substantially larger in the case of the bands appearing in the lower frequency regions (below $900 \mathrm{~cm}^{-1}$; Figure $7 d-f)$. In the case of the $\gamma \mathrm{C}-\mathrm{H}$ symmetric mode, which in the monomer absorbs at around $825 \mathrm{~cm}^{-1}$, the calculations predicted considerable blue shifts $\left(\mathrm{ca} .20 \mathrm{~cm}^{-1}\right)$ for the units in the aggregates that act as H-bond donors, in perfect agreement with the experimental observations (see Figure 7d). Also in agreement with the calculations, the frequency of the $\gamma \mathrm{C}-\mathrm{H}$ mode originating in the $\mathrm{H}$-bond acceptor molecule in the dimer $\left(826 \mathrm{~cm}^{-1}\right)$ was found to be nearly the same as in the monomer. A similar situation occurs in the case of the second $\gamma \mathrm{C}-\mathrm{H}$ symmetric vibration occurring as a doublet of bands at ca. $720 \mathrm{~cm}^{-1}$ in the monomer (see Figure 7e). 


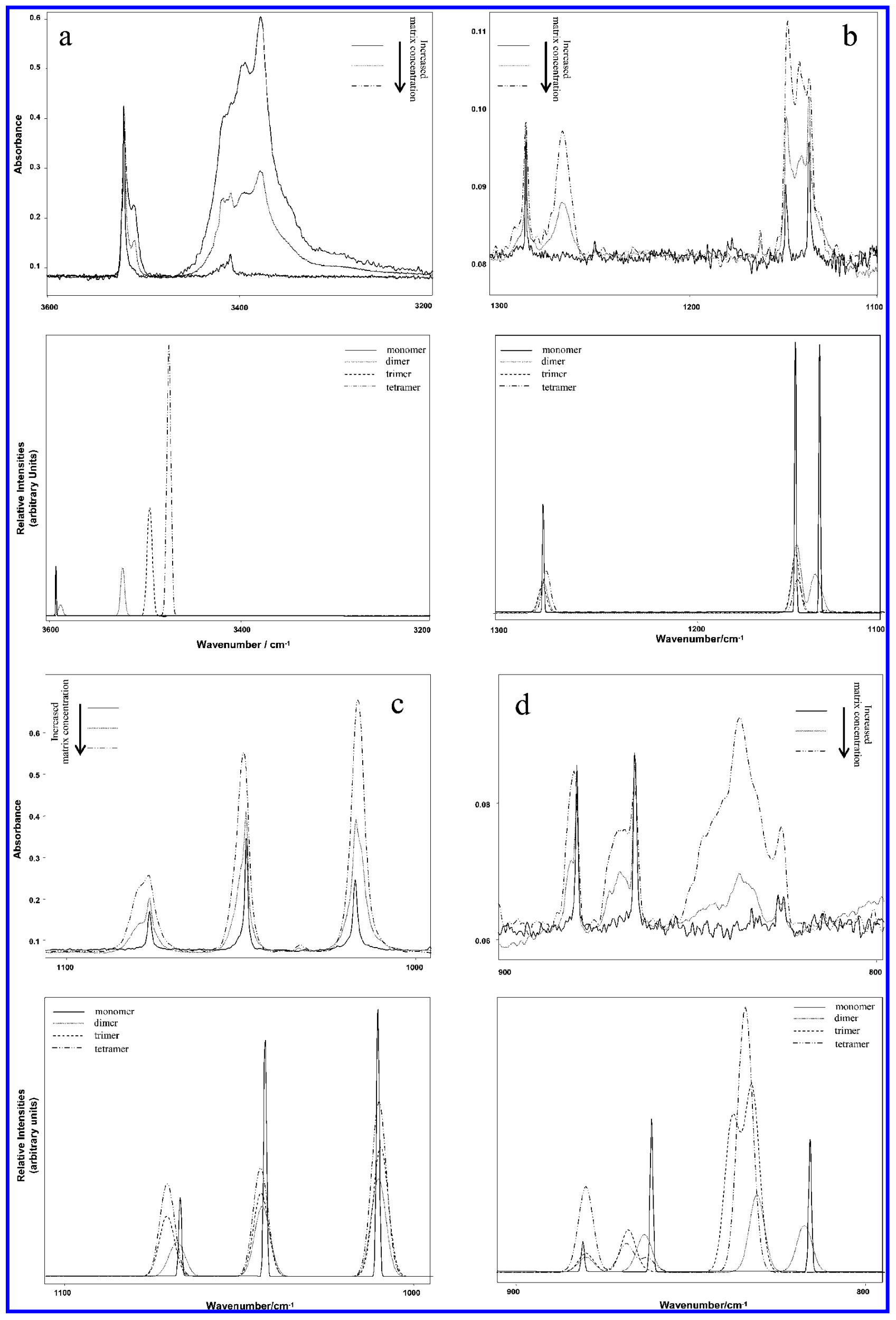




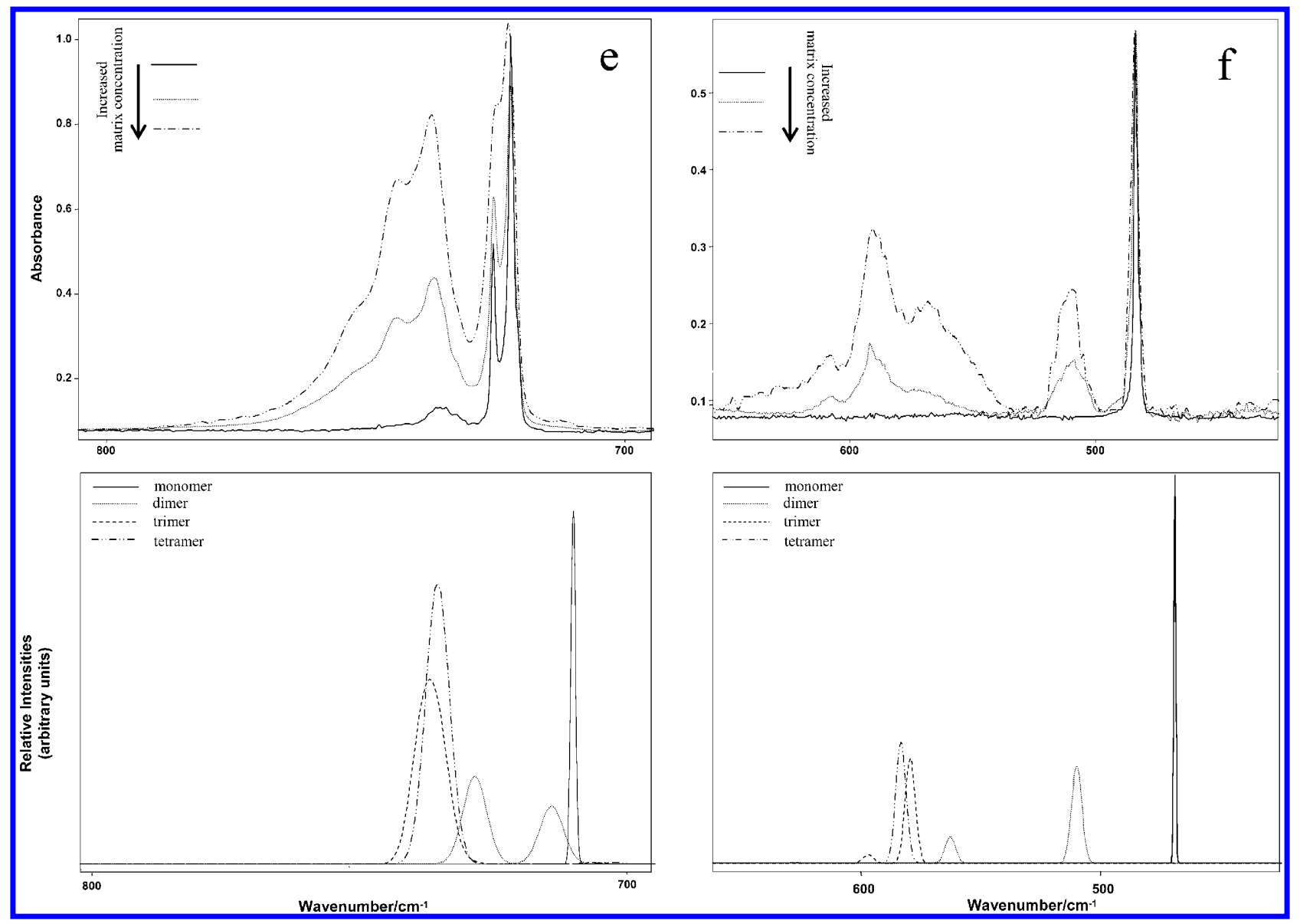

Figure 7. Experimental spectra of matrix-isolated pyrrole in argon matrixes obtained immediately after deposition $(T=9 \mathrm{~K})$ for different pyrrole/ matrix ratios and calculated spectra for the monomer, dimer, and most stable trimer and tetramer. In the calculated spectra, the bandwidth of the Gaussian functions used to simulate the spectrum of the monomer $\left(0.1 \mathrm{~cm}^{-1}\right)$ was chosen to be narrower than those used to simulate the spectra of the aggregates $\left(0.5 \mathrm{~cm}^{-1}\right)$, in order to enable an easier graphical comparison with the experimental data. Hence, the relative peak intensities are not comparable. However, the relative integral intensities were kept as they were obtained in the calculations and are directly comparable. (a) $3600-3200 \mathrm{~cm}^{-1}$ region. (b) $1300-1100 \mathrm{~cm}^{-1}$ region. (c) $1100-1000 \mathrm{~cm}^{-1}$ region. (d) $900-800 \mathrm{~cm}^{-1}$ region. (e) $800-700 \mathrm{~cm}-1$ region. (f) $700-400 \mathrm{~cm}^{-1}$ region.

As already mentioned, the $\gamma \mathrm{N}-\mathrm{H}$ mode could also be expected to be a good spectroscopic probe of the H-bonding in pyrrole aggregates. The relevant spectral region is displayed in Figure $7 \mathrm{f}$ for spectra obtained from matrixes with different concentrations of pyrrole. The frequency of this mode in the monomer was found to be ca. $483 \mathrm{~cm}^{-1}$ (in argon), i.e., slightly larger than that found in the gas phase $\left(474.4 \mathrm{~cm}^{-148}\right)$. The blue shift observed upon changing from the gas-phase to the matrix-isolated compound clearly reveals that the matrix packing forces make more difficult the out-of-the-plane movement of the $\mathrm{N}-\mathrm{H}$ hydrogen atom (i.e., as expected, increase the force constant associated with this vibration). In the dimer, the "free" $\mathrm{N}-\mathrm{H}$ group of the $\mathrm{H}$-bond acceptor molecule is predicted by the calculations to give rise to a $\gamma \mathrm{N}-\mathrm{H}$ vibration blue shifted by ca. $40 \mathrm{~cm}^{-1}$. The experimental value was found to be 30 $\mathrm{cm}^{-1}$, in relatively good agreement with the theoretical predictions. Note that the ca. $10 \mathrm{~cm}^{-1}$ difference between the theoretical and observed shifts results essentially from the difference between the frequency of the matrix-isolated monomer and that of the monomer in vacuum (or in the gas phase). Then, the calculations seem to take into due account the direct effects of the dimerization on the $\gamma \mathrm{N}-\mathrm{H}$ frequency of the $\mathrm{H}$-bond acceptor molecule in the dimer. The blue shifts due to the $\mathrm{H}$-bonding in the $\mathrm{H}$-bond donor molecules in the aggregates were predicted to be much larger (greater than ca. $100 \mathrm{~cm}^{-1}$ ) and reflect the relative strengths of the hydrogen bonds in the different aggregates, increasing with the size of the aggregate.
It was found ${ }^{75}$ that the red shift of the $v \mathrm{~N}-\mathrm{H}$ stretching mode due to $\mathrm{H}$-bond formation and the blue shift of the corresponding $\gamma \mathrm{N}-\mathrm{H}$ band correlate to each other as $[\Delta \gamma(\mathrm{N}-\mathrm{H})]^{2}=2.5$ $[\Delta \nu(\mathrm{N}-\mathrm{H})]^{1 / 2}-18$, where $[\Delta \gamma(\mathrm{N}-\mathrm{H})]^{2} \equiv 10^{-4}\left[\gamma(\mathrm{N}-\mathrm{H})^{2}-\right.$ $\left.\gamma_{o}(\mathrm{~N}-\mathrm{H})^{2}\right], \gamma_{o}(\mathrm{~N}-\mathrm{H})$ is the $\gamma \mathrm{N}-\mathrm{H}$ observed wavenumber of the monomer, and $\Delta v(\mathrm{~N}-\mathrm{H})$ is the red shift of the $v \mathrm{~N}-\mathrm{H}$ stretching band. With the use of this empirical relationship, the $\gamma \mathrm{N}-\mathrm{H}$ frequencies of the donor molecules in the different aggregates were estimated from the observed red shifts of $v \mathrm{~N}-\mathrm{H}$ as being $560 \mathrm{~cm}^{-1}$ (dimer), $577 \mathrm{~cm}^{-1}$ (trimer), and $594 \mathrm{~cm}^{-1}$ (tetramer). The observed bands are centered at 560, 570, and $590 \mathrm{~cm}^{-1}$, respectively (the DFT-calculated frequencies are 562.1, 579.5, and 583.4 $\mathrm{cm}^{-1}$; see also Figure 7f and Table 4).

Vibrational Spectra of the Pure Compound at Low Temperature. As described in the experimental section, pure pyrrole vapor was deposited onto the cold substrate of the cryostat, in order to obtain an amorphous film of the compound. The sample was then annealed up to a temperature above the glass transition, leading to the crystalline phase. Figure 8 shows the spectra collected immediately after deposition of the solid layer of pyrrole (amorphous state), in a stage where the crystallization has taken place partially and after complete crystallization of the compound.

To the best of our knowledge, no data have been reported previously for the low-temperature amorphous phase and only Loisel and Lorenzelli, in 1967, reported IR data on the crystalline phase of pyrrole at $77 \mathrm{~K}^{57}$ Table 5 shows the 
TABLE 4: Experimental and Calculated [DFT (B3LYP)/6-311++G(d,p)] Wavenumbers and Intensities for the Different Aggregates of Pyrrole ${ }^{a}$

\begin{tabular}{|c|c|c|c|c|c|c|c|c|c|}
\hline \multirow{3}{*}{$\begin{array}{l}\text { approximate } \\
\text { description }\end{array}$} & \multirow{3}{*}{$\begin{array}{c}\text { type of } \\
\text { aggregate }\end{array}$} & \multirow{2}{*}{\multicolumn{2}{|c|}{$\begin{array}{l}\text { experimental } \\
\text { wavenumber }\end{array}$}} & \multicolumn{6}{|c|}{ calculated } \\
\hline & & & & \multicolumn{2}{|c|}{$\operatorname{dimer}\left(C_{s}\right)$} & \multicolumn{2}{|c|}{ trimer (cyclic; $\left.C_{3 h}\right)$} & \multicolumn{2}{|c|}{ tetramer (cyclic; $\left.C_{4 h}\right)$} \\
\hline & & Ar matrix & Xe matrix & wavenumber $^{b}$ & intensity & wavenumber $^{b}$ & intensity & wavenumber $^{b}$ & intensity \\
\hline \multirow[t]{4}{*}{$v \mathrm{~N}-\mathrm{H}$} & $\mathrm{D}$ & 3510 & & $3588.0\left(\mathrm{~A}^{\prime}\right)$ & 76.0 & & & & \\
\hline & D & $3418 / 3409$ & & $3523.3\left(\mathrm{~A}^{\prime}\right)$ & 329.6 & & & & \\
\hline & $\mathrm{T}$ & 3396 & & & & $3495.0\left(\mathrm{E}^{\prime}\right)$ & 959.7 & & \\
\hline & Tet, $\mathrm{H}$ & 3378 & & & & & & $3475.1\left(\mathrm{E}_{\mathrm{u}}\right)$ & 1879.8 \\
\hline \multirow[t]{3}{*}{$\nu \mathrm{C}=\mathrm{C}_{\text {as }}$} & $\mathrm{D}$ & 1533 & & $1537.5\left(\mathrm{~A}^{\prime \prime}\right)$ & 0.9 & & & & \\
\hline & D & 1528 & & $1530.7\left(\mathrm{~A}^{\prime \prime}\right)$ & 3.4 & & & & \\
\hline & $\mathrm{T}$, Tet & 1520 & & & & $1521.8\left(\mathrm{~A}^{\prime \prime}\right)$ & 5.2 & $1521.4\left(\mathrm{~A}_{\mathrm{u}}\right)$ & 6.5 \\
\hline \multirow[t]{2}{*}{$\delta \mathrm{C}-\mathrm{H}_{\text {as }}$} & Agr & 1267 & & $1280.0\left(\mathrm{~A}^{\prime \prime}\right)$ & 0.6 & $1280.1\left(\mathrm{~A}^{\prime \prime}\right)$ & 0.2 & $1279.5\left(\mathrm{~A}_{\mathrm{u}}\right)$ & 1.7 \\
\hline & & & & $1278.9\left(\mathrm{~A}^{\prime \prime}\right)$ & 0.7 & $1279.5\left(\mathrm{E}^{\prime}\right)$ & 1.0 & & \\
\hline \multirow[t]{4}{*}{ breathing } & Tet & 1148 & & & & & & $1146.0\left(\mathrm{E}_{\mathrm{u}}\right)$ & 1.4 \\
\hline & $\mathrm{T}$ & 1146 & & & & $1145.7\left(\mathrm{E}^{\prime}\right)$ & 2.6 & & \\
\hline & $\mathrm{D}$ & 1142 & & $1146.4\left(\mathrm{~A}^{\prime}\right)$ & 0.8 & & & & \\
\hline & & & & $1144.5\left(\mathrm{~A}^{\prime}\right)$ & 2.3 & & & & \\
\hline \multirow{2}{*}{$\delta \mathrm{N}-\mathrm{H}_{\mathrm{ip}}$} & $\mathrm{D}$ & 1140 & & $1135.7\left(\mathrm{~A}^{\prime \prime}\right)$ & 1.5 & & & & \\
\hline & & & & $1131.9\left(\mathrm{~A}^{\prime \prime}\right)$ & 0.7 & & & & \\
\hline \multirow[t]{2}{*}{$\delta \mathrm{C}-\mathrm{H}_{\mathrm{sym}}$} & Agr & 1079 & 1083 & $1068.9\left(\mathrm{~A}^{\prime}\right)$ & 8.7 & $1071.4\left(\mathrm{~A}^{\prime \prime}\right)$ & 4.6 & $1070.6\left(\mathrm{E}_{\mathrm{u}}\right)$ & 59.2 \\
\hline & & & 1081 & $1067.2\left(\mathrm{~A}^{\prime}\right)$ & 15.1 & $1070.8\left(\mathrm{E}^{\prime}\right)$ & 35.0 & & \\
\hline \multirow[t]{2}{*}{$\delta \mathrm{C}-\mathrm{H}_{\text {as }}$} & Agr & 1049 & 1051 & $1043.5\left(\mathrm{~A}^{\prime \prime}\right)$ & 42.3 & $1043.7\left(\mathrm{~A}^{\prime \prime}\right)$ & 53.3 & $1043.8\left(\mathrm{~A}_{\mathrm{u}}\right)$ & 69.3 \\
\hline & & & 1050 & $1041.2\left(\mathrm{~A}^{\prime \prime}\right)$ & 4.7 & $1040.7\left(\mathrm{E}^{\prime}\right)$ & 0.4 & & \\
\hline \multirow[t]{2}{*}{$\delta \mathrm{C}-\mathrm{H}_{\mathrm{sym}}$} & Agr & 1016 & 1015 & $1010.3\left(\mathrm{~A}^{\prime}\right)$ & 24.4 & $1010.7\left(\mathrm{~A}^{\prime \prime}\right)$ & 4.5 & $1009.9\left(\mathrm{E}_{\mathrm{u}}\right)$ & 111.2 \\
\hline & & & 986 & $1009.9\left(\mathrm{~A}^{\prime}\right)$ & 38.3 & $1009.6\left(\mathrm{E}^{\prime}\right)$ & 79.4 & & \\
\hline \multirow[t]{2}{*}{$\delta \mathrm{C}-\mathrm{N}-\mathrm{C}$} & $\mathrm{Ag}$ & 883 & 882 & $881.4\left(\mathrm{~A}^{\prime}\right)$ & 0.2 & $880.1\left(\mathrm{E}^{\prime}\right)$ & 1.0 & $880.0\left(\mathrm{E}_{\mathrm{u}}\right)$ & 5.2 \\
\hline & & & & $879.6\left(\mathrm{~A}^{\prime}\right)$ & 0.7 & & & & \\
\hline$\gamma \mathrm{C}-\mathrm{H}_{\text {as }}$ & Tet & 872 & & & & & & $862.4\left(\mathrm{~A}_{\mathrm{u}}\right)$ & 0.8 \\
\hline \multirow[t]{3}{*}{$\delta \mathrm{C}-\mathrm{C}-\mathrm{C}_{\text {as }}$} & $\mathrm{T}$ & 869 & 867 & & & $868.0\left(\mathrm{~A}^{\prime \prime}\right)$ & 2.5 & & \\
\hline & $\mathrm{D}$ & 868 & & $863.3\left(\mathrm{~A}^{\prime \prime}\right)$ & 2.2 & & & & \\
\hline & & & & $862.5\left(\mathrm{~A}^{\prime \prime}\right)$ & 0.1 & & & & \\
\hline \multirow[t]{4}{*}{$\gamma \mathrm{C}-\mathrm{H}_{\mathrm{sym}}$} & T, Tet & 838 & 832 & & & $838.1\left(\mathrm{~A}^{\prime \prime}\right)$ & 9.1 & $834.5\left(\mathrm{E}_{\mathrm{u}}\right)$ & 16.0 \\
\hline & $\mathrm{T}$ & 835 & & & & $833.1\left(\mathrm{E}^{\prime}\right)$ & 11.0 & & \\
\hline & D & 832 & & $831.1\left(\mathrm{~A}^{\prime}\right)$ & 4.6 & & & & \\
\hline & D & 826 & & $817.5\left(\mathrm{~A}^{\prime}\right)$ & 2.8 & & & & \\
\hline \multirow[t]{4}{*}{$\gamma \mathrm{C}-\mathrm{H}_{\mathrm{sym}}$} & $\mathrm{H}$ & 752 & 738 & & & & & & \\
\hline & T, Tet. & 744 & 734 & & & $735.4\left(\mathrm{E}^{\prime}\right)$ & 554.5 & $734.1\left(\mathrm{E}_{\mathrm{u}}\right)$ & 672.6 \\
\hline & D & 738 & 731 & $727.3\left(\mathrm{~A}^{\prime}\right)$ & 209.8 & $729.5\left(\mathrm{~A}^{\prime \prime}\right)$ & 7.7 & & \\
\hline & D & 725 & 723 & $713.5\left(\mathrm{~A}^{\prime}\right)$ & 138.9 & & & & \\
\hline \multirow{6}{*}{$\begin{array}{l}\tau \text { ring }_{\text {sym }} \\
\gamma \mathrm{N}-\mathrm{H}\end{array}$} & Tet & & 645 & & & & & $672.9\left(\mathrm{E}_{\mathrm{u}}\right)$ & 29.4 \\
\hline & $\mathrm{T}$ & 608 & $598(?)$ & & & $597.1\left(\mathrm{~A}^{\prime \prime}\right)$ & 8.6 & & \\
\hline & Tet & 590 & $593 / 589$ & & & & & $583.4\left(\mathrm{E}_{\mathrm{u}}\right)$ & 123.2 \\
\hline & $\mathrm{T}$ & 570 & 583 & & & $579.5\left(\mathrm{E}^{\prime}\right)$ & 106.1 & & \\
\hline & D & 560 & n.o. & $562.8\left(\mathrm{~A}^{\prime}\right)$ & 27.2 & & & & \\
\hline & $\mathrm{D}$ & 509 & 514 & $510.0\left(\mathrm{~A}^{\prime}\right)$ & 98.9 & & & & \\
\hline
\end{tabular}

${ }^{a}$ Wavenumbers in $\mathrm{cm}^{-1}$, calculated intensities in $\mathrm{km} \mathrm{mol}^{-1} . v$, bond stretching; $\delta$, bending; $\gamma$, rocking; $\tau$ torsion; ip, in-plane; sym, symmetric; as, antisymmetric; n.o., not observed; $\mathrm{M}=$ monomer; $\mathrm{D}=$ dimer; $\mathrm{T}=$ trimer; Tet $=$ tetramer; $\mathrm{H}=$ higher order aggregates; $\mathrm{Agr}=\mathrm{D}, \mathrm{T}, \mathrm{Tet}, \mathrm{H}$. ${ }^{b}$ Scaled by 0.978 .

assignments now proposed for both the amorphous and crystalline phases and compares them with those made by Klotz et al. ${ }^{48}$ for the pure liquid.

As could be anticipated, the spectrum of the amorphous phase closely reproduced that of the liquid phase. Upon increasing the temperature of the sample, structural reorganizations were induced which can be followed spectroscopically. At a temperature of ca. $150 \mathrm{~K}$, the crystallization of the compound was observed. In different samples the exact temperature varies slightly $( \pm 5 \mathrm{~K})$ as expected taking into consideration that glassyto-crystalline phase transitions are usually strongly dependent on a series of experimental parameters which are impossible to reproduce exactly, such as, for example, pressure, concentration, and dispersion of the material in the matrix.

The extension of the changes with temperature suffered by a given band is a measure of the participation of the molecular fragments involved in the $\mathrm{H}$-bonding in the vibration associated with that band. ${ }^{75}$ In general, an increase of structural order leads to a pronounced narrowing, intensification, and frequency shift of the bands due to vibrations with significant contribution from the H-bonded moieties. In the present case, it can be expected that these effects occur essentially in the bands ascribable to vibrations with relatively significant contributions from the $\mathrm{N}-\mathrm{H}$ group. The bands due to $v \mathrm{~N}-\mathrm{H}$ (around $3370 \mathrm{~cm}^{-1}$ ) and $\gamma \mathrm{N}-\mathrm{H}$ (ca. $580 \mathrm{~cm}^{-1}$ ) clearly follow this trend (see Figure 8a,c). Following the expected trends, ${ }^{75}$ the stretching vibration red shifts upon going from the glassy state to the crystalline phase, while the out-of-plane bending vibration increases its frequency, clearly revealing that the strength of the hydrogen bonds increases. Besides these bands, whose behavior could easily be anticipated, a significant number of other bands do also vary considerably upon phase transition. This result reveals that in the H-bonded species the vibrational coupling is considerably more extended than in the monomer. In particular, the results show that the out-of-plane $\gamma \mathrm{N}-\mathrm{H}$ coordinate couples extensively with the symmetric torsional ring vibration $\left(\tau_{\text {ring }}\right.$ sym; which in the crystal gives rise to the doublet of bands at 657 and 673 $\mathrm{cm}^{-1}$; Figure $8 \mathrm{c}$ ) and the two $\gamma \mathrm{CH}$ symmetric rocking vibrations (assigned to the bands appearing in the $750 \mathrm{~cm}^{-1}$ region and ca. $840 \mathrm{~cm}^{-1}$; Figure $\left.8 \mathrm{c}\right)$. The $\delta \mathrm{N}-\mathrm{H}$ in-plane bending 

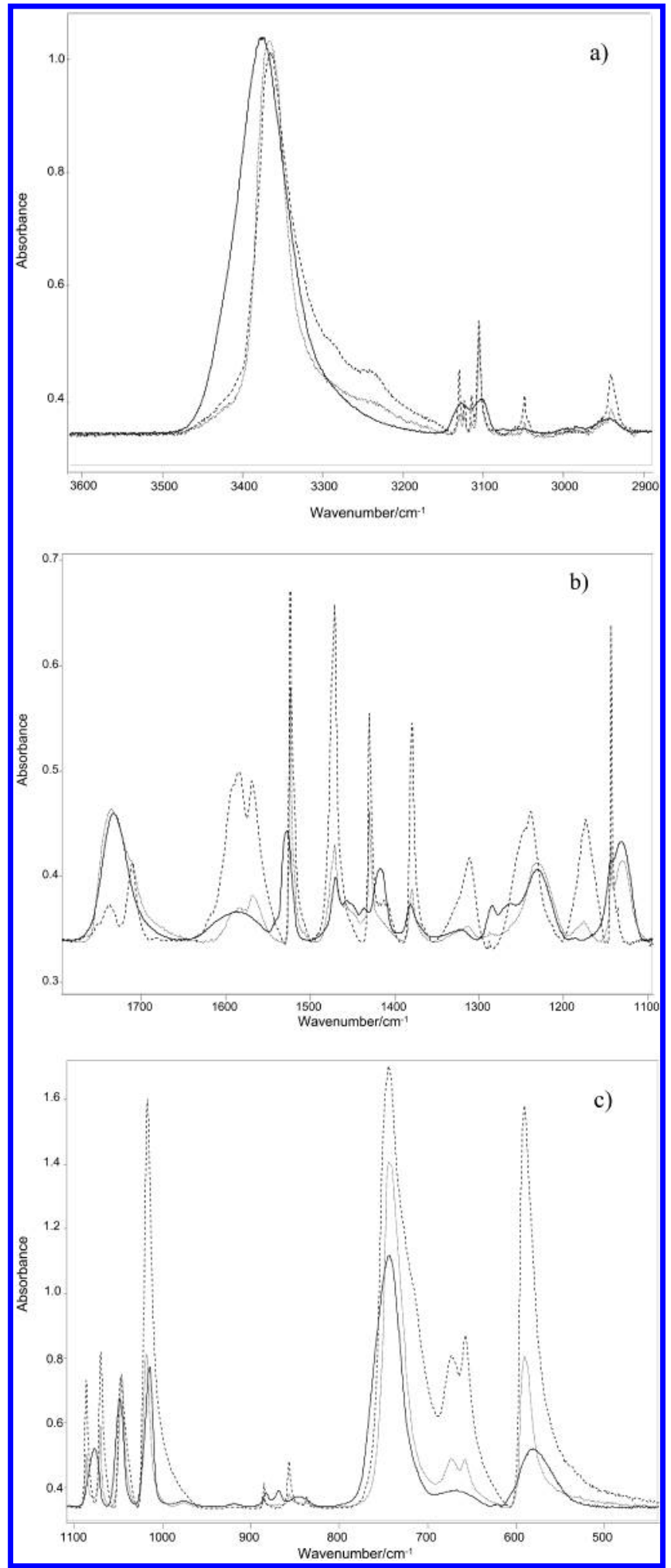

Figure 8. Infrared spectra of pyrrole as a solid amorphous layer at 9 $\mathrm{K}(-)$, partially crystallized sample obtained after annealing the solid amorphous layer at $150 \mathrm{~K}(\cdots)$, and fully crystalline sample (- - ). (a) $3600-2900 \mathrm{~cm}^{-1}$ region. (b) $1800-1100 \mathrm{~cm}^{-1}$ region. (c) $1100-$ $450 \mathrm{~cm}^{-1}$ region.

coordinate was found to be delocalized even in the monomer. ${ }^{52}$ The spectra of the solid phases show that in the case of the $\mathrm{H}$-bonded species this coordinate contributes significantly to the bands at ca. $860(\delta \mathrm{CCC}$ as.), $1430(\nu \mathrm{C}-\mathrm{N}$ as. $)$, and 1525 $\mathrm{cm}^{-1}(\nu \mathrm{C}=\mathrm{C}$ as.), all of them showing a considerable intensification and narrowing upon crystallization (Figure 8b,c). Very interestingly, the bands at ca. 1130 and $1290 \mathrm{~cm}^{-1}$, which are
TABLE 5: Experimental and Calculated [DFT(B3LYP)/ 6-311 $++G(d, p)]$ Wavenumbers for the Liquid, Crystal, and the Amorphous States of Pyrrole ${ }^{a}$

\begin{tabular}{|c|c|c|c|}
\hline mode & liquid $^{48 b}$ & amorphous & crystal \\
\hline$\nu \mathrm{N}-\mathrm{H}$ & 3409 & 3375 & 3366 \\
\hline$\nu \mathrm{C}-\mathrm{H}_{\mathrm{sym}}$ & (3135) & 3125 & 3130 \\
\hline$v \mathrm{C}-\mathrm{H}_{\text {as }}$ & (3135) & 3125 & 3124 \\
\hline$v \mathrm{C}-\mathrm{H}_{\mathrm{sym}}$ & (3114) & 3102 & 3115 \\
\hline$\nu \mathrm{C}-\mathrm{H}_{\text {as }}$ & 3102 & 3102 & 3105 \\
\hline $2 \times \delta \mathrm{N}-\mathrm{H}$ & 3054 & 3051 & 3049 \\
\hline $2 \times v \mathrm{C}=\mathrm{C}_{\mathrm{svm}}$ & 2941 & 2941 & 2940 \\
\hline$\nu \mathrm{C}-\mathrm{N}_{\mathrm{as}}+\delta \mathrm{C}-\mathrm{H}_{\mathrm{as}}$ & 2700 & 2703 & 2700 \\
\hline$\nu \mathrm{C}-\mathrm{C}+$ breathing & 2570 & 2557 & 2562 \\
\hline$\tau$ ring ${ }_{\text {as }}+\delta \mathrm{N}-\mathrm{H}_{\mathrm{ip}}$ & n.o. & 1750 & 1750 \\
\hline $2 \times \gamma \mathrm{C}-\mathrm{H}_{\text {as }}$ & 1736 & 1736 & 1736 \\
\hline$\gamma \mathrm{C}-\mathrm{H}_{\text {as }}+\gamma \mathrm{C}-\mathrm{H}_{\mathrm{sym}}$ & 1704 & 1714 & 1710 \\
\hline$\gamma \mathrm{C}-\mathrm{H}_{\text {as }}+\gamma \mathrm{C}-\mathrm{H}_{\text {as }}^{\prime}$ & 1582 & 1587 & 1584 \\
\hline$\gamma \mathrm{C}-\mathrm{H}_{\mathrm{sym}}+\gamma \mathrm{C}-\mathrm{H}_{\mathrm{sym}}$ & 1568 & $158 /$ & \\
\hline or $\delta \mathrm{C}-\mathrm{H}_{\text {sym }}+\gamma \mathrm{N}-\mathrm{H}$ & 1530 & $\begin{array}{l}1568 \\
1526\end{array}$ & 1523 \\
\hline $\begin{array}{l}\nu \mathrm{C}=\mathrm{C}_{\text {as }} \\
\gamma \mathrm{C}-\mathrm{H}_{\mathrm{as}}+\gamma \mathrm{C}-\mathrm{H}_{\mathrm{sym}}\end{array}$ & $\begin{array}{l}1530 \\
\text { n.o. }\end{array}$ & $\begin{array}{l}1526 \\
\text { n.o. }\end{array}$ & $\begin{array}{l}1523 \\
1519\end{array}$ \\
\hline$\gamma\left(11_{\text {as }}\right.$ i $11_{\mathrm{sym}}$ & & 1470 & \\
\hline$\nu \mathrm{C}=\mathrm{C}_{\mathrm{s}}$ & 1467 & $\begin{array}{l}1455 \\
1449\end{array}$ & $\begin{array}{l}1474 \\
1471\end{array}$ \\
\hline$\nu \mathrm{C}-\mathrm{N}_{\mathrm{as}}$ & 1418 & $\begin{array}{l}1436 \\
1416\end{array}$ & 1430 \\
\hline$\nu \mathrm{C}-\mathrm{C}_{\mathrm{sym}}$ & 1383 & 1382 & 1380 \\
\hline$\gamma \mathrm{C}-\mathrm{H}_{\mathrm{as}}+\tau \mathrm{ring}$ as & 1320 & 1333 & 1312 \\
\hline$\delta \mathrm{C}-\mathrm{H}_{\text {as }}$ & 1286 & 1285 & 1288 \\
\hline $2 \times \tau$ ring $_{\text {as }}$ & 1240 & $\begin{array}{l}1265 \\
1249\end{array}$ & 1231 \\
\hline $2 \times \gamma \mathrm{N}-\mathrm{H}$ & n.o. & 1187 & 1175 \\
\hline breathing & 1143 & 1145 & 1145 \\
\hline$\delta \mathrm{N}-\mathrm{H}_{\mathrm{ip}}$ & 1143 & 1135 & 1131 \\
\hline$\delta \mathrm{C}-\mathrm{H}_{\mathrm{sym}}$ & 1075 & 1076 & $\begin{array}{l}1086 \\
1069\end{array}$ \\
\hline$\delta \mathrm{C}-\mathrm{H}_{\text {as }}$ & 1047 & 1047 & 1046 \\
\hline$\delta \mathrm{C}-\mathrm{H}_{\mathrm{sym}}$ & 1013 & 1014 & 1018 \\
\hline$\delta \mathrm{CNC}$ & 880 & 882 & 885 \\
\hline$\delta \mathrm{CCC}_{\mathrm{as}}$ & 867 & 868 & 857 \\
\hline$\gamma \mathrm{C}-\mathrm{H}_{\mathrm{as}}$ & (869) & n.o. & n.o. \\
\hline$\gamma \mathrm{C}-\mathrm{H}_{\text {sym }}$ & 840 & 844 & 837 \\
\hline & & 758 & 751 \\
\hline$\gamma \mathrm{C}-\mathrm{H}_{\mathrm{sym}}$ & 735 & 742 & 743 \\
\hline & & & 719 \\
\hline$\gamma \mathrm{C}-\mathrm{H}_{\text {as }}$ & (713) & n.o. & n.o. \\
\hline$\tau$ ring $_{\text {sym }}$ & 649 & 665 & $\begin{array}{l}673 \\
657\end{array}$ \\
\hline$\tau$ ring as & $(621)$ & $621(?)$ & n.o. \\
\hline$\gamma \mathrm{N}-\mathrm{H}$ & 560 & 580 & 590 \\
\hline
\end{tabular}

${ }^{a}$ Wavenumbers in $\mathrm{cm}^{-1} . \nu$, bond stretching; $\delta$, bending; $\gamma$, rocking; $\tau$, torsion; ip, in-plane; sym, symmetric; as, antisymmetric; n.o., not observed. ${ }^{b}$ Values in parentheses are Raman data and correspond to the vibrations that in the monomer are of $\mathrm{A}_{2}$ symmetry.

also ascribed to vibrations with a significant contribution from the $\delta \mathrm{N}-\mathrm{H}$ in-plane bending coordinate, though becoming narrower upon crystallization, experience a considerable intensity reduction (Figure 8b). There is also another group of bands that are significantly affected by crystallization and that originate in vibrations that are not expected to have significant contributions either from $\delta \mathrm{N}-\mathrm{H}$ in-plane or $\gamma \mathrm{N}-\mathrm{H}$ out-of-plane bending coordinates. These bands appear at ca. $885(\delta \mathrm{CNC}), 1145$ (breathing), and $1470 \mathrm{~cm}^{-1}(\nu \mathrm{C}=\mathrm{C}$ sym), and it is easy to notice that, in all the cases, in the $\mathrm{H}$-bonded species the dominant coordinate implies a significant change in the $\mathrm{NH} \cdots \pi \mathrm{H}$-bond distance during the vibration. This fact justifies the observed behavior. Note that the $\mathrm{H}$-bond effects on the band profiles and frequency position are also observable in the overtone and combination bands involving the coordinates that give rise to fundamental bands which follow the above-described behavior upon phase transition. This is clearly visible, for instance, in 
the bands at ca. $3050(2 \times \delta \mathrm{N}-\mathrm{H}), 2940(2 \times \nu \mathrm{C}=\mathrm{C}$ s. $)$, and $2560 \mathrm{~cm}^{-1}(\nu \mathrm{C}-\mathrm{C}+$ breathing $)-$ see Figure $8 \mathrm{a}$.

An interesting observation extracted from the crystal-state spectrum of pyrrole is related with the presence in this spectrum of a band at ca. $1175 \mathrm{~cm}^{-1}$, which is absent in the spectra of both the gas-phase $\mathrm{e}^{48}$ and matrix-isolated pyrrole; in the spectra of the amorphous phase a very low-intensity band appears near this frequency that can be the corresponding band for the compound in this phase, though this is uncertain, since no equivalent band has been observed for the liquid. ${ }^{48}$ The 1175 $\mathrm{cm}^{-1}$ band in the spectrum of the crystal is here assigned to the first overtone of the $\gamma \mathrm{N}-\mathrm{H}$ out-of-plane bending mode, whose fundamental in this phase is observed at $590 \mathrm{~cm}^{-1}$. This band could be expected to considerably intensify in the crystal, as compared with both the liquid and amorphous states, this fact justifying its nonobservation in these experimental conditions. In the gas phase and for the matrix-isolated pyrrole, the $\gamma \mathrm{N}-\mathrm{H}$ vibration absorbs at a much lower frequency (474.4 and ca. 483 $\mathrm{cm}^{-1}$, respectively; see Table 2), and as discussed previously, its overtone gives rise to bands in the $960-995 \mathrm{~cm}^{-1}$ region (see Table 3 and Figure 6).

\section{Conclusion}

In this work, the structures of pyrrole and its self-aggregates up to the tetramer were optimized at the DFT(B3LYP)/ 6-311++G(d,p) level. Three different trimers and four different tetramers were found in the corresponding potential energy surfaces at this level of theory, with the cyclic structures corresponding to the most stable species. The $R(\mathrm{~N}-\mathrm{H})$ and $R(\mathrm{NH} \cdots \pi)$ distances were successfully correlated with the relative strength of the $\mathrm{H}$-bonds in the different aggregates studied.

H-bond cooperativity was also studied for all the aggregates analyzed. The cooperative enhancement was shown to increase with the cluster size, with $C\left[\Delta H_{0}(\mathrm{HB})\right]$ attaining the maximum value of $\sim 40 \%$ for the cyclic tetramer. The strength of the H-bonds among members of the same cluster size was also shown to be the main factor determining their relative energies.

Matrix isolation low-temperature FTIR spectroscopic studies allowed, for the first time, the isolation of monomeric pyrrole in argon and xenon matrixes. The IR vibrational signatures of pyrrole aggregates (up to tetramer), obtained either after annealing of the matrixes or by increasing the matrix concentration, were studied by comparing the experimental results with the calculated spectra for these species. The experimental results confirm the theoretical predictions regarding the $\mathrm{H}$-bond cooperative effects in the pyrrole aggregates and fully support the assignments of the gas-phase spectrum of the compound made by Klotz et al. ${ }^{48}$

The IR spectra of both the low-temperature amorphous state and the crystalline phase of pyrrole were also obtained and interpreted. The transition from the glassy state to the crystalline phase was observed around $150 \mathrm{~K}$. The analysis of the spectra revealed that, in the crystalline phase, several modes have significant contributions from the $\mathrm{N}-\mathrm{H}$ group, which can be clearly identified by taking into consideration the temperature dependence of the corresponding bands.

Acknowledgment. This work was supported by FEDER, "Fundação para a Ciência e a Tecnologia", Lisbon (Research Projects POCTI/QUI/43366/2001 and POCTI/QUI/33495/2000, and Grant SFRH/BPD/11499/2002), CONICET and Agencia Nacional de Promoción Científica y Tecnológica- PICT 13080, Argentina.

\section{References and Notes}

(1) Fischer, H.; Orth, H. Akademische Verlag: Die Chemie des Pyrrols; Leipzig, 1934, 1937, 1940; Vol. I.

(2) Zhang, Q.; Zhou, X.; Yang, H. J. Power Sources 2004, 125, 141.

(3) Wang, J.; Neoh, K.; Kang, E. Thin Solid Films 2004, 446, 205.

(4) Kim, S.; Oh, K.; Bahk, J. J. Appl. Polvm. Sci. 2004, 91, 4064.

(5) Ghosh, P.; Kar, S. J. Appl. Polvm. Sci. 2004, 91, 3737.

(6) Bousalem, S.; Yassar, A.; Basinska, T.; Miksa, B.; Slomkowski, S.; Azioune, A.; Chehimi, M. Polvm. Adv. Technol. 2003, 14, 820.

(7) Kanakaraju, R.; Kolandaivel, P. Int. J. Mol. Sci. 2002, 3, 777.

(8) Wilcox, W.; Goldstein, J. J. Chem. Phys. 1952, 20, 1656.

(9) Bak, B.; Christensen, D.; Hansen, L.; Rastrup-Andersen, J. J. Chem. Phvs. 1956, 24, 720 .

(10) Schomaker, V.; Pauling, L. J. Am. Chem. Soc. 1939, 61, 1769

(11) Kofod, H.; Sutton, L.; Jackson, J. J. Chem. Soc. 1952, 1467.

(12) Nygaard, L.; Nielsen, J.; Kirchheiner, J.; Maltesen, G.; RastrupAndersen, J.; Soerensen, G. J. Mol. Struct. 1969, 3, 491.

(13) Columberg, G.; Bauder, A. J. Chem. Phvs. 1997, 106, 504.

(14) Burcl, R.; Handy, N.; Carter, S. Spectrochim. Acta, Part A 2003, $59,1881$.

(15) Roos, B.; Malmqvist, P.; Molina, V. J. Chem. Phvs. 2002, 116, 7526.

(16) Simandiras, E.; Handy, N.; Amos, R. J. Phvs. Chem. 1988, 92, 1739.

(17) Lubich, L.; Oss, S. J. Chem. Phvs. 1997, 106, 5379.

(18) Kofranek, M.; Kovár, T.; Karpfen, A.; Lischka, H. J. Chem. Phvs. 1992, 96, 4464.

(19) Nagano, H.; Tsuneda, T.; Hashimoto, T.; Hirao, K. J. Chem. Phvs 1996, 104, 2312.

(20) Trofimov, A.; Schirmer, J. Chem. Phvs. 1997, 214, 153.

(21) Palmer, M.; Walker, I.; Guest, M. Chem. Phvs. 1998, 238, 179.

(22) Christiansen, O.; Gauss, J.; Stanton, J.; Jørgensen, P. J. Chem. Phys. 1999, 51, 2276.

(23) Melluki, A.; Liévin, J.; Herman, M. Chem. Phvs. 2001, 271, 239.

(24) Stefov, V.; Pejov, L.; Soptrajanov, B. J. Mol. Structure 2003, 649, 231.

(25) Pejov, L. Chem. Phys. Lett. 2002, 339, 269

(26) Pejov, L. J. Ouantum Chem. 2003, 92, 516

(27) Lukes, V.; Breza, M.; Biskupic, S. Theor. Chem. Acc. 1999, 101, 319.

(28) Park, H.; Lee, S. Chem. Phvs. Lett. 1999, 301, 487.

(29) Sobolewski, A.; Domcke, W. Chem. Phvs. Lett. 2000, 321, 479

(30) Hobza, P.; Selzle, H.; Schlag, E. J. Phys. Chem. 1993, 97, 3937.

(31) Hobza, P.; Selzle, H.; Schlag, E. J. Am. Chem. Soc. 1994, 116 3500 .

(32) Hobza, P.; Selzle, H.; Schlag, E. J. Chem. Phvs. 1990, 93, 5893

(33) Smith, G.; Jaffe, R. J. Phvs. Chem. 1996, 100, 9624.

(34) Goddard, R.; Heinemann, O.; Krüger, C. Acta Crvstallogr. 1997, C53, 1846 .

(35) Fuson, N.; Josien, M.; Powell, R.; Utterback, E. J. Chem. Phvs 1952, 20, 145.

(36) Cataliotti, R.; Paliani, G. Can. J. Chem. 1976, 54, 2451.

(37) Xie, Y.; Fan, K.; Boggs, J. Mol. Phvs. 1986, 58, 401.

(38) Coblentz, W. Investigation of Infrared Spectra; Carnegie Institute: Washington, DC, 1905.

(39) Lord, R.; Miller, F. J. Chem. Phvs. 1942, 10, 328.

(40) Mirone, P. Gazz. Chim. Ital. 1956, 86, 165.

(41) Morcillo, J.; Orza, J. An. R. Soc. Esp. Fis. Quim. 1960, B56, 231, 253.

(42) Orza, J.; Rico, M.; Barrachina, M. J. Mol. Spectrosc. 1966, 20, 233.

(43) Orza, J.; Escribano, R. J. Chem. Soc., Faradav Trans. 2 1985, 81, 653.

(44) Scott, D. J. Mol. Spectrosc. 1971, 37, 77.

(45) Kostic, R.; Rakovic, D.; Stepanyan, S.; Davidova, I.; Gribov, L. J. Chem. Phys. 1995, 102, 3104.

(46) Douketis, C.; Reilly, J. J. Chem. Phvs. 1992, 96, 3431.

(47) Snavely, D.; Blackburn, F.; Ranasinghe, Y.; Walters, V.; González del Riego, M. J. Phvs. Chem. 1992, 96, 3599.

(48) Klotz, T.; Chirico, R.; Steele, W. Spectrochim. Acta, Part A 1994, 50,765 .

(49) Mellouki, A.; Georges, R.; Herman, M.; Snavely, D.; Leytner, S. Chem. Phvs. 1997, 220, 311.

(50) Mellouki, A.; Auwera, J.; Herman, M. J. Mol. Spectrosc. 1999, 193, 195.

(51) Held, A.; Herman, M. Chem. Phys. 1995, 190, 407.

(52) Lee, S.; Boo, B. J. Phvs. Chem. 1996, 100, 15073.

(53) Navarro, R.; Orza, J. An. Ouim. 1983, 79, 557.

(54) Navarro, R.; Orza, J. An. Ouim. 1984, 80, 59.

(55) Navarro, R.; Orza, J. An. Ouim. 1985, 81, 5.

(56) Ambroseo, J.; Hochstrasser, R. J. Chem. Phvs. 1988, 89, 5956.

(57) Loisel, J.; Lorenzelli, V. Spectrochim. Acta, Part A 1967, 23, 2903. 
(58) Callegari, A.; Pearman, R.; Choi, S.; Engels, P.; Srivastava, H.; Gruebele, M.; Lehmann, K.; Scoles, G. Mol. Phys. 2003, 101, 551.

(59) Sánchez-Sanchez, M.; Blasco, T. J.Am. Chem. Soc. 2002, 124, 3443.

(60) Gaudioso, J.; Ho, W. J. Am. Chem. Soc. 2001, 123, 10095.

(61) Cesaro, S.; Dobos, S.; Stirling, A. Vib. Spectrosc. 1999, $20,59$.

(62) Reva, I.; Stepanian, S.; Adamowicz, L.; Fausto, R. J. Phvs. Chem. A 2001, 105, 4773.

(63) Frisch, M. J.; Trucks, G. W.; Schlegel, H. B.; Scuseria, G. E.; Robb, M. A.; Cheeseman, J. R.; Zakrzewski, V. G.; Montgomery, J. A., Jr.; Stratmann, R. E.; Burant, J. C.; Dapprich, S.; Millam, J. M.; Daniels, A D.; Kudin, K. N.; Strain, M. C.; Farkas, O.; Tomasi, J.; Barone, V.; Cossi, M.; Cammi, R.; Mennucci, B.; Pomelli, C.; Adamo, C.; Clifford, S. Ochterski, J.; Petersson, G. A.; Ayala, P. Y.; Cui, Q.; Morokuma, K.; Malick, D. K.; Rabuck, A. D.; Raghavachari, K.; Foresman, J. B.; Cioslowski, J.; Ortiz, J. V.; Stefanov, B. B.; Liu, G.; Liashenko, A.; Piskorz, P.; Komaromi, I.; Gomperts, R.; Martin, R. L.; Fox, D. J.; Keith, T.; Al-Laham, M. A.; Peng, C. Y.; Nanayakkara, A.; Gonzalez, C.; Challacombe, M.; Gill, P. M. W.; Johnson, B. G.; Chen, W.; Wong, M. W.; Andres, J. L.; Head-Gordon, M.; Replogle, E. S.; Pople, J. A. Gaussian 98, revision A.9; Gaussian, Inc.: Pittsburgh, PA, 1998.
(64) Becke, A. J. Chem. Phvs. 1993, 98, 5648

(65) Lee, C.; Yang, W.; Parr, R. Phvs. Rev. B 1988, 37, 785.

(66) Frisch, M.; Head-Gordon, M.; Pople, J. Chem. Phvs. Lett. 1990, 166, 281.

(67) Fuller, J. F.; Szczepanski, J.; Vala, M. Chem. Phvs. Lett. 2000, $323,86$.

(68) Schoone, K.; Smets, J.; Ramaekers, R.; Houben, L.; Adamowicz, L.; Maes, G. J. Mol. Struct. 2003, 649, 61.

(69) Gómez-Zavaglia, A.; Fausto, R. Vib. Spectrosc. 2003, 33, 105. (70) Borba, A.; Gómez-Zavaglia, A.; Lapinski, L.; Fausto, R. Phvs. Chem. Chem. Phys. 2004, 6, 2101.

(71) Csaszar, P.; Pulay, P. J. Mol. Struct. (THEOCHEM) 1984, 114, 31.

(72) De Frees, D.; McLean, A. J. Chem. Phvs. 1985, 82, 333.

(73) Boys, S.; Bernardi, F. Mol. Phys. 1970, 19, 553.

(74) Belinka, B. A.; Hassner, A.; Hendler, J. M. J. Org. Chem. 1981, 46,632 .

(75) Rozenberg, M. Sh. Spectrochim. Acta 1996, A52, 1559.

(76) Bugalho, S. S. C. S.; Maçôas, E. M. S.; Cristiano, M. L. S.; Fausto, R. Phvs. Chem. Chem. Phvs. 2001, 3, 3541.

(77) Iogansen, A. V. Spectrochim. Acta 1999, A55, 1585. 